\title{
COLEÇÕES BIOLÓGICAS DO JARDIM BOTÂNICO DO RIO DE JANEIRO À LUZ DAS METAS DA GSPC/CDB: ONDE ESTAREMOS EM 2020?
}

\author{
Rafaela Campostrini Forzza ${ }^{1,2}$, \\ Anibal Carvalho Jr.', \\ Antônio Carlos S.Andrade', \\ Luciana Franco', \\ Luís Alexandre Estevão', \\ Viviane S. Fonseca-Kruel', \\ Marcus A. Nadruz Coelho', \\ Neusa Tamaio', \\ Daniela Zappi'
}

\section{RESUMO}

O conjunto de coleções biológicas sob a guarda do Jardim Botânico do Rio de Janeiro (JBRJ) vai além das exsicatas do herbário e plantas vivas do arboreto, e inclui também coleções em estufas, xiloteca, carpoteca, bancos de sementes e de DNA, cultura de fungos e coleção etnobotânica. Juntas estas diferentes coleções contabilizam cerca de 665 mil espécimes, que contribuem para ampliar o conhecimento da flora neotropical.A partir do final do século $X X$ e início do século $X X I$, com a mudança de paradigma envolvendo a conservação e o uso racional da biodiversidade do planeta, as coleções biológicas e seus dados associados saíram de uma posição marginal para ocupar uma posição central na discussão que quantifica, qualifica, mapeia e estuda o potencial de uso da biodiversidade. Neste novo cenário, os jardins botânicos e suas coleções estão completamente inseridos nas tarefas relacionadas a atingir as metas da biodiversidade delineadas pela CDB/GSPC. Neste artigo descrevemos quais metas envolvem diretamente as coleções do JBRJ e analisamos tanto a participação como as limitações dos nossos acervos para apoiar o país no cumprimento das metas da GSPC 2020.

\section{PALAVRAS-CHAVE}

Conservação da Flora, Documentação da Biodiversidade, Informação Taxonômica, Sistemas de Curadoria

\begin{abstract}
The biologic collections housed at the Jardim Botânico do Rio de Janeiro (JBRJ) go beyond herbarium exsiccatae and the arboretum, comprising also a wood-collection, carpological collection, greenhouse collection, seed and DNA baks, fungal culture and ethnobotany collections. Together the different collections add up to 665 thousand specimens, contributing substantially towards the neotropical flora knowledge. From the end of the $20^{\text {th }}$ century and the beginning of the $2 \mathrm{I}^{\text {st }}$, the paradigm regarding conservation and rational use of the world's biodiversity changed, and the biological collections and their data moved from a marginal position to occupy a central role in the discussion that quantifies, qualifies, maps and studies the potential of use of biodiversity. Within this new scene, botanical gardens and their collections are totally inserted in accomplishing the tasks regarding the biodiversity targets proposed by the CBD/GSPC. In this article we map the targets that involve directly the collections of the JBRJ and analyse the contributions and limitations of our holdings in supporting the country to reach the targets of the GSPC 2020.
\end{abstract}

\section{KEYWORDS}

Biodiversity Documentation, Conservation of the Flora, Curation Systems, Taxonomic Information 


\section{Introdução}

A Convenção da Diversidade Biológica (CDB 1992) e a Systematics Agenda 2000 (1994) impulsionaram a mudança de paradigma no cenário mundial no que diz respeito ao papel das coleções biológicas, destacando a importância da publicação de seus dados primários no fluxo de informações sobre a biodiversidade. Como parte de sua inserção neste cenário, o Brasil definiu as coleções biológicas como componentes básicos de suporte ao desenvolvimento científico e inovação tecnológica, afirmando que o fortalecimento da ciência em benefício da sociedade depende da promoção do amplo acesso a dados e informações sobre a biodiversidade brasileira (KURY et al. 2006). O Jardim Botânico do Rio de Janeiro se inseriu completamente neste novo paradigma, com os dados primários de seus acervos digitalizados e disponíveis via web a partir 2005 (FORZZA et al. 2008, GONZALEZ, 2009).

Durante a reunião da Convenção da Diversidade Biológica $(C D B)$ realizada em Nagoya em outubro de 2010, representantes dos diversos governos assinaram uma nova versão modificada e atualizada da Estratégia Global para a Conservação das Plantas (GSPC). A nova estratégia tem uma visão centrada no seguinte raciocínio:"Sem plantas não há vida. $O$ funcionamento do planeta e nossa sobrevivência dependem das plantas. Esta estratégia tem como objetivo deter a perda contínua da diversidade vegetal mundial". Dentro desta visão, foram estabelecidos cinco objetivos, subdivididos em 16 metas, a serem atingidas até 2020 (https://www.cbd.int/gspc/strategy.shtml). Neste cenário, as coleções biológicas desempenham um papel central, com impacto direto sobre cinco das I6 metas, e afetam indiretamente a maioria das outras em maior ou menor grau. Hoje, tanto a infraestrutura de pesquisa do Jardim Botânico do Rio de Janeiro como suas coleções estão ativamente envolvidas na coordenação e realização da flora on-line (Meta I); na avaliação do status de conservação das espécies (Meta 2); na conservação ex situ de espécies ameaçadas (Meta 8); na conservação da diversidade genética de plantas cultivadas de importância socioeconômica (Meta 9); e na manutenção ou aumento do conhecimento e de inovações das práticas indígenas e locais (Meta 13) (https://www.cbd.int/gspc/strategy.shtml).

O presente artigo tem como objetivo apresentar as coleções do JBRJ e expor o papel e as limitações destas no que diz respeito ao atendimento das metas da GSPC/CDB 20 I I-2020 pelo Brasil.

\section{Coleções botânicas do JBRJ: histórico e cenário atual}

A história do herbário do Jardim Botânico do Rio de Janeiro e de suas coleções correlatas se iniciou no dia 25 de março de 1890, no momento em que o naturalista João Barbosa Rodrigues assumiu a direção do Jardim Botânico do Rio de Janeiro, e com suas próprias palavras descreveu: "O local conhecido como Jardim Botânico não é atualmente mais que um mero parque de recreio, não se encontrando ahi a menor base para estudo, quando justamente esses estabelecimentos não são creados senão para escolas práticas de historia natural, no ramo a que se destinam." (Relatório apresentado em 12 de junho de 1890 - Fonte: Rodrigues I893) (VALENTE et al. 200 I, FORZZA et al. 2008, 20I5a).

Com o apoio do chefe do governo Provisório da República dos Estados Unidos do Brasil, o general Manoel Deodoro da Fonseca, Barbosa Rodrigues criou, em 1892, o Museu Botânico (hoje Museu do Meio Ambiente), a Biblioteca (que hoje leva o seu nome) e o herbário. $O$ acervo inicial deste herbário foi constituído por 25.000 amostras doadas por D. Pedro II (VALENTE et al. 200I). O visionário Barbosa Rodrigues ia além, vislumbrando a vocação deste 
Rafaela Campostrini Forzza, Anibal Carvalho Jr., Antônio Carlos S.Andrade, Luciana Franco, Luís Alexandre Estevão,Viviane S. Fonseca-Kruel, Marcus A. Nadruz Coelho, Neusa Tamaio, Daniela Zappi

herbário como guardião de espécimes vegetais e, principalmente, concebendo que esta coleção de plantas seria ampliada e utilizada através dos séculos para consolidar o estudo da flora brasileira. Com este objetivo definido, ele próprio realizou diversas expedições científicas e contratou profissionais denominados "naturalistas viajantes" para coletar em várias localidades, de norte a sul do Brasil. Também criou o cargo não remunerado de "correspondentes do Jardim Botânico" que era ocupado por pessoas indicadas pelo diretor com a finalidade de remeterem plantas vivas e secas ao JBRJ, enriquecendo expressivamente os acervos (VALENTE et al. 200 I, FORZZA et al. 2008). Barbosa Rodrigues também mantinha vasta correspondência com diretores de jardins botânicos de outros países, obtendo sementes, amostras vivas e espécimes por intercâmbio para enriquecer as coleções.

Ao longo do século $X X$ ocorreram muitas transformações no herbário, constituindo mudanças relacionadas à estrutura administrativa do Jardim Botânico e mesmo do país. Entre 1915 e 1931, sob a direção de Antônio Pacheco Leão, o herbário e as coleções vivas receberam novo impulso graças à dedicada atuação de vários botânicos, dentre estes Adolpho Ducke, Johan Löfgren, João Geraldo Kuhlmann e Paulo Campos Porto e, em 1933, recebeu o reforço de Alexander Curt Brade (Bediaga et al. 2008). Em 1938 o herbário do Jardim Botânico foi registrado na International Association for Plant Taxonomy (IAPT), recebendo o acrônimo RB, (VALENTE et al. 200I).

Durante as décadas seguintes os pesquisadores do JBRJ organizaram inúmeras expedições para coleta de plantas em diferentes regiões do país. Da mesma forma, o intercâmbio com herbários nacionais e internacionais foi incrementado e novas amostras incorporadas. Todo este trabalho propiciou o enriquecimento do acervo, ampliando assim sua importância científica para o conhecimento da flora do Brasil, sendo reconhecido como uma coleção estratégica do país (KURY et al. 2006, VALENTE et al. 200I, FORZZA et al. 2008). Atualmente, o herbário conta com cerca de 620.000 exsicatas, sendo 7.500 tipos nomenclaturais, e entre 15 e 20 mil novas amostras são incorporadas anualmente (FORZZA et al. 20I5a).

Uma grande parte da área do JBRJ está destinada à manutenção de suas coleções vivas.A fundação destas coleções remonta à fundação do próprio JBRJ, sendo a primeira a ser estabelecida com a chegada da família real ao Brasil, em I808, quando D. João VI fundou uma fábrica de pólvora na antiga propriedade de Rodrigo de Freitas (antigo engenho de cana-de-açúcar). Em junho daquele mesmo ano criaria o Real Horto Botânico, onde as primeiras espécies foram introduzidas. Tratava-se de plantas produtoras de especiarias, tais como bauniIha, pimenta e canela. A partir daí várias outras foram ofertadas como doação ao príncipe regente, oriundas de várias partes do mundo, dentre elas o chá e a cana-de-açúcar. Nas décadas de 1820 e 1830 eram colhidas anualmente cerca de $340 \mathrm{~kg}$ de folhas de chá no Real Horto (COELHO, 2008, BEDIAGA et al. 2008).

Em 1890, Joaquim de Campos Porto ficou à frente do Real Jardim conferindo um cunho cultural e científico à coleção existente, reorganizando os viveiros, aumentando o número das plantas vivas e refazendo a classificação dos exemplares cultivados. De 1890 a 1909, João Barbosa Rodrigues resolveu reunir as plantas por afinidades e dividiu o Jardim Botânico por seções. Barbosa Rodrigues contabilizou a época 7I famílias, 4 I I gêneros e 838 espécies nativas e exóticas no arboreto. Depreende-se que, até essa época, o acervo de plantas vivas vinha sendo cultivado sem registros. Somente após esse período os dados sobre as plantas vivas foram reunidos no fichário das "Plantas Cultivadas do Jardim Botânico" (COELHO 2008). 
Atualmente, a coleção viva, ou arboreto, ocupa uma área de 54 hectares, dos quais 38,8 hectares pertencem à área verde que compreende 40 seções, distribuídas em 194 canteiros e 122 aléias, batizadas com nomes da espécie predominante, dos antigos diretores ou naturalistas de renome internacional, e seis coleções temáticas (Cactário, Orquidário, Bromeliário, Insetívoras, Plantas Medicinais e Coleção de Sombra). Na área do arboreto também estão representados alguns dos diferentes domínios fitogeográficos do Brasil (Amazônia, Mata Atlântica, Cerrado e Caatinga), além de exemplares dos continentes Africano, Americano, Europeu,Asiático e Oceania, sendo que os países com maior presença em espécies cultivadas são China, Índia, Madagascar, Malásia e México. O acervo atual é de 15.815 espécimes que correspondem a 2.941 espécies (JBRJ 2016).

Ao longo dos séculos $X X$ e $X X I$ outras coleções botânicas foram sendo estabelecidas, sendo elas: carpoteca, xiloteca, bancos de DNA e de sementes, coleção em meio líquido, cultura de fungos e etnobotânica.

A xiloteca, criada em 1942, abriga um conjunto de amostras preparadas, registradas e incorporadas segundo técnicas específicas. Seguindo normas internacionais, possui registro próprio e é reconhecida pelo acrônimo RBw. Seu uso é destinado à pesquisa científica (anatomia, taxonomia, ecologia, etc.) e também como instrumento de consulta e referência para identificação de amostras comerciais. Neste campo a coleção é fundamental para a correta identificação das diversas espécies madeireiras, auxiliando profissionais envolvidos com a fiscalização, extração e comercialização de madeiras e também solucionando conflitos que porventura surjam entre clientes, fornecedores e fiscais (BARROS et al. 200 I). Atualmente, há 37 xilotecas no Brasil (BARROS \& CORADIN, 20I5) e a do Jardim Botânico do Rio de Janeiro é uma das mais importantes, com um acervo de cerca de 10.200 amostras e uma coleção de lâminas com 26 mil unidades.

O banco de sementes foi criado na década de 1980 e tem como objetivo a conservação ex situ de sementes de espécies nativas como recurso natural, permitindo o seu uso futuro em programas de recuperação e reintrodução de espécies ameaçadas, atendendo ao cumprimento de metas da Convenção sobre Diversidade Biológica (CDB). Também é uma ferramenta fundamental no desenvolvimento de pesquisas e no fomento de sementes para produção de mudas no Horto Florestal do Jardim Botânico. Conta atualmente com cerca de 3.000 acessos de espécies nativas e exóticas e realiza intercâmbio com instituições científicas nacionais através do Index Seminum (http://www.jbrj.gov.br/pesquisa/ banco_sem/Index_seminum.pdf).

O banco de DNA, criado em 2004, conta atualmente com 5.776 amostras de espécies da flora brasileira. As amostras de DNA armazenadas vêm sendo utilizadas em pesquisas taxonômicas, de estrutura genética de populações, filogenia e filogeografia, gerando dados, que somados a informações ecológicas, subsidiam a proposição de medidas conservacionistas de espécies e ecossistemas ameaçados. Bancos de DNA representam também uma nova abordagem para a preservação da diversidade genética das espécies, que pode ser explorada hoje, ou futuramente, para a bioprospecção de genes envolvidos na produção de substâncias e/ou processos de importância biotecnológica.

A coleção de cultura de fungos, iniciada em 2010 , visa conservar um dos grupos de organismos mais promissores em projetos de bioremediação ambiental, os quais exercem importante papel nos ciclos biogeoquímicos. Também são amplamente utilizados na alimentação, além de participarem da maioria dos processos biotecnológicos empregados na produção de compostos comerciais ou para transformação de substratos em produtos de maior valor agregado e 
Rafaela Campostrini Forzza, Anibal Carvalho Jr., Antônio Carlos S.Andrade, Luciana Franco, Luís Alexandre Estevão, Viviane S. Fonseca-Kruel, Marcus A. Nadruz Coelho, Neusa Tamaio, Daniela Zappi

constituem importantes patógenos de plantas de importância econômica. $\bigcirc$ acervo preserva estes organismos para estudos atuais e futuros assim como para eventual utilização na recomposição de ambientes, na indústria ou em atividades relacionadas. Atualmente o acervo conta com cerca de 270 fungos em cultura, mantidos por repicagens periódicas, das quais I 20 pelo método de água destilada (Castellani) e 22 pelo método de liofilização. A maioria das amostras de fungos foi isolada a partir de plantas com sintomas de doenças fúngicas coletadas em diversos viveiros de mudas utilizadas em reflorestamento.

A mais recente coleção correlata ao herbário é a Etnobotânica, registrada em 2012 no Index Herbariorum. Atualmente, esta possui um acervo de 187 itens que representam materiais de plantas selecionados pela sua importância de uso, tanto na forma de matéria-prima quanto em parte ou em produtos processados e/ou artefatos. Acreditamos que esses espécimes têm uma longa história de uso, fato que pode ser eficaz na transmissão do conhecimento, não apenas sobre a parte da planta utilizada, mas também da maneira como vem sendo processada e/ou utilizada. $O$ principal objetivo desta coleção é garantir o registro e a preservação do conhecimento relacionado ao uso dos vegetais por grupos humanos. Neste sentido, os espécimes vêm sendo adquiridos e incorporados como testemunho do conhecimento local relacionado à história e uso das espécies. Considerando as peculiaridades deste acervo, as amostras são reconhecidas pelo acrônimo RBetno e seguem as regras estabelecidas pela Convenção sobre Diversidade Biológica (CDB) e a Lei sobre Acesso a Recursos Genéticos (Brasil 200I), especialmente relacionadas à conservação de recursos genéticos e seu conhecimento tradicional associado. A RBetno é regida também pelos códigos de ética das sociedades profissionais (Declaração de Belém 2004; International Society of Ethnobiology 2006), que tratam da proteção das informações etnobotânicas relacionadas, especialmente aos dados sensíveis dos materiais. A RBetno visa construir uma ponte entre a diversidade biológica e cultural, e pode vir a ser um recurso valioso para o estudo das plantas utilizadas no passado, presente e no futuro.

\section{Publicação de dados e imagens via web}

Considerando a necessidade de tornar mais acessíveis as informações associadas aos seus acervos biológicos, 2005 marcou o início no JBRJ de uma iniciativa ambiciosa para a época, visando capturar em uma base de dados todas as informações contidas nas amostras botânicas da instituição. A equipe de Tecnologia da Informação do JBRJ desenvolveu um Sistema de Informação (JABOT) capaz de armazenar e tornar disponível de maneira eficiente e ágil as informações contidas nas amostras (GONZALEZ 2009). Hoje, após 10 anos de trabalho e investimentos oriundos de diferentes fontes quase $100 \%$ dos dados primários contidos nas coleções botânicas do JBRJ estão disponíveis através do sitewww.jbrj.gov.br/jabot.

O processo de captura de imagens do acervo teve início em 2008, com a digitalização dos tipos nomenclaturais através do projeto GPI (Global Plants Initiative), onde cerca de 15.000 imagens foram produzidas. Também através desta iniciativa, toda a coleção histórica do botânico francês Antoine-Laurent Apollinaire Fée, doada por Pedro II para a fundação do herbário, foi digitalizada. Em 2010, através do financiamento do programa Reflora/CNPq, teve início a captura de imagens dos demais espécimes do acervo RB, hoje praticamente concluído e com todas as imagens podendo ser consultadas via web. Os dados 
e/ou imagens também são publicados no Herbário Virtual Reflora (http://reflora.jbrj.gov.br), no SiBBr (http://www.sibbr.gov.br) e no GBIF (http://www.gbif. org). Exceção é a coleção etnobotânica, que por motivos de proteção ao conhecimento tradicional pela legislação vigente, possui limitação quanto à publicação dos dados (FORZZA et al. 2015a,b).

Um total de 8.665 mil indivíduos da coleção viva também podem ser acessados pelo endereço http://aplicacoes.jbrj.gov.br/jabot/v2/arboreto.php, onde cada um deles pode ser localizado no mapa do arboreto, alguns com fotos. A busca dos indivíduos, pode ser realizada pelo nome científico, nome popular, coletor, localização e número de tombo. O recurso "minha localização"(street view) também está disponível.

Além publicados para a comunidade em geral, todos os dados podem ser consumidos máquina-máquina através do Portal de Dados (http://dados.jbrj.gov. br). Esse conjunto de informações é atualizado diariamente, uma vez que novas amostras, novas determinações e novas imagens são incorporadas todos os dias.

\section{Delineamento das Metas da GSPC sobre a atual situação das coleções}

Um dos grandes desafios enfrentados pelo JBRJ durante os próximos anos será contribuir para que o Brasil alcance as metas estabelecidas pela GSPC/CDB até 2020. Neste sentido, as coleções biológicas possuem um papel central, estando diretamente relacionadas com cinco das 16 metas que serão abordadas a seguir.

\section{Meta I - Flora on-line de todas as plantas conhecidas}

O JBRJ, através do Herbário Virtual Reflora (http://reflora.jbrj.gov.br), disponibiliza on-line tanto as mais de 600 mil imagens de seu herbário, quanto aquelas provenientes do repatriamento das amostras depositadas nos herbários europeus e americanos e de outros importantes acervos nacionais (FORZZA et al. 20I5b). Esses dados e imagens são indispensáveis para embasar a taxonomia e a nomenclatura da Flora do Brasil 2020 (www.floradobrasil.jbrj.gov.br).

Por outro lado, apesar dos esforços dos botânicos realizados nas últimas décadas, os dados disponíveis no momento indicam que o número de coletas oriundas das Regiões Norte e Centro-Oeste está muito aquém do necessário para o conhecimento de toda a diversidade vegetal destas regiões (SHEPHERD 2005; HOPKINS 2007; FORZZA et al. 20I0, 20I2, BFG 20I5). Considerando que os sistemas atuais somam as duplicatas de cada acervo, o número real de amostras por $\mathrm{km} 2$ é, possivelmente, muito menor do que aquele necessário para conhecer a ocorrência e real distribuição das espécies (para maiores detalhes vide SHEPHERD, 2005; SOBRAL \& STEHMANN, 2009; MORIM \& LUGHADHA, 20I5). Desse modo, a ampliação do número de espécimes por $\mathrm{km} 2$ depositados em coleções biológicas provenientes de regiões pouco amostradas é uma necessidade premente para atingir de modo satisfatório a Meta I. O JBRJ, com seu dinamismo, contatos e reputação, encontra-se numa posição estratégica para aumentar a cobertura de coletas no território nacional, devendo contribuir para que isto ocorra na próxima década.

Meta 2 - Avaliação de risco de extinção de todas as espécies da flora e, até onde for possível, guiar ações de conservação

Até o momento, das 34.826 mil espécies de plantas vasculares e briófitas ocorrentes no território brasileiro (BFG 20I5, PRADO et al. 20I5, COSTA \& 
Rafaela Campostrini Forzza, Anibal Carvalho Jr., Antônio Carlos S.Andrade, Luciana Franco, Luís Alexandre Estevão, Viviane S. Fonseca-Kruel, Marcus A. Nadruz Coelho, Neusa Tamaio, Daniela Zappi

PERALTA 20I5), 6.050 (I7\%) foram avaliadas quanto ao risco de extinção pelo Centro Nacional de Conservação da Flora (http://cncflora.jbrj.gov.br/portal). Grande parte das informações passíveis de serem utilizadas atualmente para avaliação de risco de extinção, seguindo os critérios da IUCN (200I), é proveniente dos dados associados aos espécimes das coleções biológicas (para maiores detaIhes vide MARTINELLI \& MORAES 20I3). Desse modo, publicar acervos on-line e ampliar o número de amostras coletadas nos diferentes domínios brasileiros é uma das principais formas de gerar dados primários para embasar as futuras avaliações de risco. Além disto, as avaliações precisam contar com uma taxonomia e nomenclatura acuradas oriundas da Flora do Brasil 2020 (Meta I).

\section{Meta 8 - Pelo menos $75 \%$ das espécies ameaçadas preservadas em coleções ex situ e $\mathbf{2 0} \%$ destas incluídas em programas de restauração e recuperação}

Nos últimos anos a missão dos jardins botânicos expandiu-se para além do foco tradicional em horticultura e vem assumindo um papel central e proativo na conservação ex situ de plantas (HAVENS et al. 2006, COSTA 20I4). Define-se por ex situ a conservação dos componentes da diversidade biológica fora de seus habitats naturais, por meio de coleções de plantas vivas, armazenamento de sementes ou coleções de plântulas em bancos in vitro, tanto para uso imediato como para potencial uso futuro (GROSS et al. 2005). Métodos de conservação ex situ são prioritários para espécies endêmicas e em perigo iminente de extinção. Esse tipo de conservação inclui métodos economicamente viáveis e que podem ser aplicados por longo prazo (WALTERS \& ENGELS I998, HAVENS et al. 2006).

O método mais tradicional de conservação ex situ, através de coleções vivas, é mais dispendioso, necessitando não apenas de espaço físico, como de capacidade de cultivo sob condições climáticas adequadas para espécies de distintos biomas, e capacidade humana especializada no cuidado de plantas vivas. Apesar dessas desvantagens, as vantagens de contar com grande diversidade plantas vivas num jardim botânico são muitas e superam, em muito, as dificuldades. Plantas vivas tem um papel educativo crucial, sendo possível traçar ligações históricas, estéticas e até mesmo emocionais entre elas e os visitantes do jardim (HAVENS et al. 2006). A presença de exemplares de espécies raras e/ou ameaçadas ao alcance do público é um recurso educativo valioso que deve ser explorado por jardins botânicos (COSTA 20I4). Uma das finalidades do acervo de espécimes vivos do JBRJ é representar tanto a flora brasileira como abrigar espécies exóticas, destinadas a estudos científicos constituindo um santuário botânico onde pesquisadores de diversas áreas encontram meios para adquirir e repassar conhecimento sobre diferentes grupos vegetais (Coelho 2008). Comparando as espécies contidas na base de dados do JBRJ (www.jbrj.gov.br/ jabot) com a atual lista de espécies ameaçadas do Brasil (MMA 20I4), podemos afirmar que a coleção de plantas vivas (estufas e arboreto) abrigam I 88 espécies ameaçadas de extinção, sendo Bromeliaceae e Orchidaceae as famílias como maior número de espécies.

Um dos métodos mais seguros, convenientes e práticos para preservação da diversidade biológica vegetal é o armazenamento de sementes, principalmente quando a espécie se reproduz de forma sexuada, quando suas sementes são tolerantes a desidratação e a integridade das amostras armazenadas pode ser garantida por longo tempo (WALTERS \& ENGELS 1998, HAVENS et al. 2006, 
ANDRADE 2007). Essa técnica é frequentemente usada como complemento aos métodos de conservação in situ, mas pode ser a única opção de conservação para algumas espécies raras e ameaçadas de extinção e visa conservar a diversidade genética contida nas populações (ENGELS et al. 2008).

A atual Lista Oficial de Espécies Ameaçadas do Brasil (MMA 20I4) considera 2.I I 3 espécies em uma das três categorias da IUCN (Vulnerável, Em Perigo e Criticamente em Perigo). Considerando que a Meta 8 estabelece que 75\% destas estejam conservadas até 2020 em coleções ex situ, é esperado que I.585 espécies sejam conservadas em bancos de sementes ou por meio de técnicas de coleções vivas ou conservação in vitro, em instituições de ensino e pesquisa nacionais. Das 600 espécies armazenadas no banco de sementes do JBRJ, 30 constam na lista oficial de ameaçadas.

O banco de DNA do JBRJ também tem muito a contribuir no âmbito da Meta 8. Árvores filogenéticas, baseadas em sequências de DNA de amostras depositadas, podem ser usadas para descobrir áreas de endemismo excepcional, para orientar atividades de coleta de germoplasma para conservação ex situ ou para estabelecer áreas prioritárias para conservação insitu.Tambémvale destacar que caracterizar a variabilidade genética contida dentro e entre as populações é essencial para o manejo adequado e conservação de espécies, em especial aquelas sob risco de extinção. Assim, o banco de DNA também vem armazenando amostras no nível de população, permitindo que perguntas importantes sejam respondidas.

Meta 9 - Pelo menos $\mathbf{7 0 \%}$ da diversidade genética de plantas cultivadas, incluindo seus parentes silvestres e outras espécies de plantas de importância socioeconômica conservadas respeitando, preservando e mantendo o conhecimento indígena e local associado.

Espécies vegetais de valor econômico atual ou potencial vêm sendo objeto de estudos através da iniciativa "Plantas para o Futuro", visando oferecer à sociedade novas opções para suprir a crescente demanda por espécies de interesse alimentício, medicinal, cosmético, aromático, entre outros. Apesar da existência, no Brasil, de um número considerável de espécies nativas já domesticadas, a utilização de recursos genéticos autóctones em escala comercial é ainda incipiente quando comparada ao seu potencial (CORADIN et al. 20I I). Ainda não é possível contabilizar o número de espécies implicadas nesta meta, e será necessário realizar estudos genéticos das populações para estabelecer a variabilidade a ser conservada. Porém, acreditamos que tanto a coleção viva como os bancos de sementes e de DNA do JBRJ encontram-se na posição de contribuir para o alcance da Meta 9, podendo também utilizar as facilidades educativas da instituição para interpretar e manter viva a informação sobre o uso das mesmas.

Meta 13 - Manutenção ou aumento, conforme o caso, do conhecimento e as inovações das práticas indígenas e locais associados com os recursos vegetais, para apoiar o uso habitual, meios de vida sustentáveis, segurança alimentar local e saúde.

Esta meta está centrada em respeitar e assegurar que os conhecimentos das comunidades locais e indígenas sobre os recursos vegetais utilizados sejam mantidos, perpetuados e valorizados pelas gerações futuras. Estes conhecimentos vêm sendo desenvolvidos a partir da experiência adquirida ao longo dos séculos e adaptados à cultura e ambiente locais, geralmente transmiti- 
Rafaela Campostrini Forzza, Anibal Carvalho Jr., Antônio Carlos S.Andrade, Luciana Franco, Luís Alexandre Estevão,Viviane S. Fonseca-Kruel, Marcus A. Nadruz Coelho, Neusa Tamaio, Daniela Zappi

dos oralmente de geração em geração na forma de histórias, canções, folclore, provérbios, valores culturais, crenças, rituais, idioma local e práticas agrícolas (CDB 20I2; IIED 20I5). O conhecimento tradicional associado inclui métodos de manejo e usos que comunidades locais e/ou tradicionais possuem sobre suas plantas (silvestres ou domesticadas), variedades ou sistemas de cultivo nos centros de origem e difusão. A riqueza deste conhecimento enumera práticas importantes para a conservação da diversidade de cultivares, assim como de espécies de importância sócioeconomica e/ou cultural. Atualmente, o conhecimento tradicional está diretamente relacionado à Herança Biocultural, que se refere ao conhecimento e às práticas das comunidades indígenas e tradicionais sobre o uso de seus recursos, a partir das variedades genéticas de culturas que se desenvolvem e às paisagens que estas criam (IIED 20I5). Estas comunidades se adaptaram a determinados climas ao longo de muitas gerações, assim, esta herança é importante para assegurar a alimentação tanto de pessoas como de animais, especificamente frente às mudanças climáticas.

As pesquisas etnobotânicas geram dados e coleções de espécimes (material vegetal testemunho, artefatos, fotografias, registros de narrativas orais, vídeos, mapas) que fundamentam a identificação e registro de indicadores das rotas de conhecimentos locais e das culturas para o desenvolvimento de cultivares, manejo comunitário da biodiversidade, critérios de seleção de espécies e a compreensão da classificação para o uso das plantas de valor sociocultural. Propiciam também a ampliação e valorização do conhecimento sobre espécies de uso medicinal e/ou alimentar relacionadas às comunidades locais que vivem nas proximidades de áreas prioritárias para conservação.

Com isso, a Meta 13 ressalta a importância dos recursos vegetais associados ao conhecimento local e/ou tradicional nas práticas tradicionais e inovadoras, como nos modos de vida, quanto à segurança alimentar e de saúde para que as gerações futuras possam se beneficiar do uso sustentável destes recursos. É complementar à Convenção da Diversidade Biológica (Artigo 8j), assim como à Meta 9 (GSPC), ao Plano de Ação Global para a Conservação e Utilização Sustentável dos Recursos Fitogenéticos para Alimentação e Agricultura (GPA), o Tratado Internacional sobre Recursos Genéticos Vegetais para Alimentação e Agricultura, Convenção Mundial do Patrimônio da UNESCO (Artigo 5a), bem como as políticas de proteção sobre a herança natural e cultural mundial através do sistema internacional de cooperação e assistência, para apoiar a longo prazo as comunidades locais e indígenas nos desafios ambientais e adaptações às mudanças climáticas (CDB 20I2; FAO 20I4; FAO 20I5).

A Coleção Etnobotânica do JBRJ contribui com a Meta 13, pois possui registros de conhecimentos etnobotânicos gerados tanto por pesquisas atuais, relacionadas as plantas medicinais e/ou medicamentos comercializados em mercados públicos no Brasil, bem como com o mapeamento de recursos vegetais úteis, especificamente do litoral fluminense. Conta ainda com pesquisas em acervos e coleções históricas internacionais para repatriamento de dados sobre a história do uso de plantas do Brasil. Nesse sentido, esta coleção agrega informações que podem auxiliar nas atividades de coleta de germoplasma, conservação ex situ, além de mapear a disponibilidade de recursos vegetais úteis, subsidiando no estabelecimento de áreas prioritárias para conservação insitu. Esta coleção apresenta registros, como: narrativas orais, vídeos, fotografias e fragmentos de madeiras (identificados a partir das técnicas de anatomia vegetal) relacionados à história das canoas artesanais contadas pelos mestres canoeiros no litoral dos estados do Rio de Janeiro e Santa Catarina. As pesquisas etnobotânicas, a par- 
tir das canoas, buscam estabelecer a rota do conhecimento tradicional desses mestres canoeiros que ainda detém a história sobre os recursos madeireiros da mata atlântica, ou seja, aborda a história ecológica da mata atlântica a partir do uso das madeiras relacionadas à pesca artesanal e os modos de vida. Com estas informações reunidas torna-se possível apoiar ações educativas, de documentação e de conservação que visam à transmissão do conteúdo contido no acervo.

\section{Perspectivas e limitações das coleções para alinhar-se às metas da GSPC 2020}

Desde 2008, o JBRJ foi incumbido de um papel central no sentido de atingir as Metas I e 2 da GSPC. A primeira através dos esforços que levaram à publicação do Catálogo de Plantas e Fungos do Brasil (FORZZA et al. 2010, Meta I de 20I0) e a segunda através da criação do Centro Nacional de Conservação da Flora (CNCFlora), que em 2013 lançou o primeiro Livro Vermelho da flora brasileira (Martinelli \& Moraes 20I3). A manutenção e avanço da Lista de espécies da Flora do Brasil (http://floradobrasil.jbrj.gov.br) e de sua conclusão em 2015 (MAIA et al. 20I5, MENEZES et al. 20I5, COSTA \& PERALTA 20I5, PRADO et al. 20I5, BFG 20I5) trouxe vantagens imediatas como a possibilidade de reconhecer com maior rapidez novas espécies a serem descritas, novos registros para o país e a diversidade específica de cada domínio fitogeográfico. Além disto, esse trabalho foi a base taxonômica para as avaliações de risco e elaboração da lista de espécies ameaçadas do Brasil. No início de 2016, o sistema de informação que hospedou o projeto Lista de Espécies da Flora do Brasil foi modificada e ampliada para ser capaz de acomodar a Flora do Brasil 2020, visando o atingimento da Meta I da GSPC.

Tanto herbário RB como os demais reunidos sob o Herbário Virtual Reflora constituem uma importante base para o projeto Flora do Brasil 2020, e sua ampliação é de extrema importância para a elaboração de uma flora nacional de qualidade, que reflita a real biodiversidade das plantas, algas e fungos. Da mesma forma, estas amostras têm impacto direto na avaliação de risco de ameaça das espécies. Como demonstrado por (MARTINELLI \& MORAES 20I3), o número de espécies ameaçadas por região é claramente vinculado ao esforço amostral (= presença de um número representativo de exsicatas em herbários).

Grande parte das coleções desidratadas do JBRJ está acondicionada adequadamente para a preservação a longo prazo (e.g. xiloteca, carpoteca, etnobotânica, herbário). Porém, mesmo tendo boa parte da infraestrutura necessária, tanto a manutenção e ampliação quanto a melhoria da capacidade instalada são um constante desafio para coleções como as do JBRJ, que incorporam anualmente grande número de novos exemplares, recebem cerca de 600 visitantes presenciais e mais de 2 milhões de consultas on-line/ano.

O incremento necessário, tanto do acervo físico quanto do virtual, abrange diversas facetas: inclusão do maior número possível de materiais históricos depositados nos grandes herbários do mundo e dos acervos nacionais através de digitalização de espécimes; aumento do acesso de botânicos a essas coleções, seja remotamente ou presencialmente; e, principalmente, o incremento de novas coletas em áreas pouco amostradas e com lacunas de conhecimento. Porém, ampliar a disponibilidade de amostras, seja através de novas coletas, seja a partir da digitalização de espécimes já incluídos nos acervos, implica na necessidade de expansão de espaços físicos e na ampliação da capacidade de armazenamento para as amostras digitais.Ambas iniciativas demandam alto nível de investimento. 
Rafaela Campostrini Forzza, Anibal Carvalho Jr., Antônio Carlos S.Andrade, Luciana Franco, Luís Alexandre Estevão, Viviane S. Fonseca-Kruel, Marcus A. Nadruz Coelho, Neusa Tamaio, Daniela Zappi

Porém, o aporte financeiro necessário para a digitalização dos acervos possibilita a geração de conhecimento de um modo muito mais rápido, além de poder gerar economia de recursos orientando que as excursões de campo sejam realizadas em locais como baixo número de amostras.

Apesar das dimensões dos compromissos assumidos pelo JBRJ, da efetividade e sucesso dos projetos supracitados, e da importância do cumprimento das Metas I e 2 para o Brasil, estes continuam sendo custeados em grande parte a partir de recursos inconstantes. Além disto, os recursos humanos altamente especializados e treinados para desempenhar as funções vitais que garantam o andamento dos projetos e manutenção dos sistemas, integrando vasta quantidade de dados e de pesquisadores, não são servidores do JBRJ.Vemos isto como um grande risco para o futuro dos projetos de digitalização, avaliação de risco das espécies e para a Flora do Brasil 2020.

Diante das ameaças sofridas atualmente pelos habitats naturais, provocadas principalmente pela destruição e deterioração mundial em larga escala (PIMM et al. 1995), verificou-se o aumento de esforços de vários países para proteger espécies vegetais silvestres em coleções vivas e bancos de sementes. Em termos da devastação dos biomas brasileiros, devido principalmente a expansão das fronteiras urbanas-agrícolas, a situação é alarmante e o número de espécies ameaçadas bastante preocupante (MARTINELLI \& MORAES 2013, MARTINELLI et al. 20I4). Neste cenário a conservação ex situ é estratégica, especialmente para espécies ameaçadas. Avaliamos que o número de espécies mantidas em coleções vivas no Brasil ainda precisa ser melhor quantificado emapeada de acordo com as espécies prioritárias tanto para o cumprimento da Meta 8 como da Meta 9. Porém, é possível afirmar, neste momento, que a cobertura oferecida pelos acervos vivos dos jardins botânicos brasileiros poderia ser em muito ampliada (para maiores detalhes vide COSTA 20I4). No âmbito desses mesmos jardins nacionais, apenas $5 \%$ destes conservam espécies prioritárias em bancos de sementes (PEREIRA \& COSTA, 20I0).

A situação das coleções vivas do JBRJ está aquém do necessário para causar um impacto significativo sobre as Metas 8, 9 e I 3 da GSPC. Para o banco de sementes, coleção de fungos e arboreto, a prioridade ainda está na definição de um foco institucional que guie o planejamento da ampliação do número de espécimes e na melhoria da infraestrutura necessária para a conservação ex situ. Apesar da existência de uma boa infraestrutura básica do banco de sementes do JBRJ, esta coleção necessita de aporte de recursos para ampliar as coletas de espécies prioritárias para conservação. Também há necessidade de obter recursos para ampliação da equipe de coleta de sementes, de novos equipamentos e para a manutenção dos mesmos, visando atender tanto a expansão como o monitoramento da coleção, especialmente com o aumento previsto na atividade de aquisição e conservação de novas amostras, à medida que mais avaliações de risco sejam realizadas (Meta 2).

Apesar da recente pequena ampliação da área "cultivada" do JBRJ, que foi utilizada para construção de estufas, o crescimento da coleção viva encontra-se extremamente limitado pela falta de espaço físico. Da mesma forma, a carência de mão de obra qualificada para o cultivo e manutenção das plantas vivas é uma limitação bastante preocupante. Um outro desafio é a atualização dos nomes científicos e identificação precisa dos espécimes com determinação incompleta, juntamente com a construção de um banco de imagens e mapeamento das plantas cultivadas, indicando claramente quais são espécies ameadas de extinção. Muito se avançou neste sentido na última década, mas ainda é preciso mais esforço. 
A manutenção e ampliação da coleção de fungos por repicagens periódicas em água destilada seria melhorada se as amostras fossem acondicionadas em câmara fria a $10 \circ C$. Isso permitiria maior espaçamento entre as repicagens, atualmente feitas trimestralmente, para intervalos semestrais. $\bigcirc$ método de preservação em água destilada também poderia ser melhorado através de acondicionamento em ambiente com temperaturas mais baixas. A ultrarefrigeração é um método recomendado mundialmente para este grupo de organismos (WOLFE \& BRYANT 200I) e com este método seria possível acondicionar maior número de amostras para efetuar pesquisas e garantir o uso tanto atual como futuro das mesmas. Assim, avaliamos que esta coleção não tem crescido significativamente por falta de técnicos e limitação de espaço físico adequado.

A coleção Etnobotânica possui infraestrutura básica para conservar um acervo com informações que transmitem memórias e saberes relacionados ao conhecimento tradicional e ao uso de plantas (artefatos, fragmentos de plantas úteis, produtos de origem vegetal, vídeos, narrativas, imagens). Para tal foi instituída a uma "Política da Coleção Etnobotânica/RBetno", que define as normas e diretrizes para consulta, assim como protocolo para inclusão de novos espécimes, levando em consideração as normas estabelecidas pela CDB e Lei sobre Acesso a Recursos Genéticos. Esta política visa salvaguardar o acervo utilizando um conjunto de ações variadas e interdependentes. Ações educativas, de documentação e de conservação reunidas visam garantir o futuro da coleção, melhorando as condições para o acondicionamento, exposição ou mesmo de transmissão do conteúdo contido no acervo. No momento pretendesse fortalecer esta coleção dentro de instituições e organizações da comunidade brasileira através do projeto "Mobilização sobre a importância de Coleções Bioculturais", que busca facilitar a transmissão multidirecional de informação sobre plantas utilizadas, assim como o registro do conhecimento a partir de coleções históricas e contemporâneas. No entanto, um dos pontos fracos deste acervo diz respeito à ausência de conservadores especializados e de ações suficientes de conservação para sua manutenção e principalmente ampliação. A coleção Etnobotânica pretende ser uma ponte entre coleções etnográficas, etnobotânicas e de botânica econômica, integrando tanto informações geradas por pesquisas etnobotânicas do JBRJ, quanto por informações repatriadas e já existentes em instituições nacionais e internacionais sobre os recursos vegetais e/ou potenciais do Brasil. Nesta perspectiva, a atuação de uma equipe interdisciplinar se faz necessária e trará benefícios aos envolvidos para o fortalecimento e ampliação desta coleção, que requer além de uma abordagem integrada, uma base mais equitativa para as coleções de pesquisa, e a capacidade de desenvolver plataformas para a transmissão de informações para uma ampla gama de usuários finais.

Apesar do grande volume de dados armazenado hoje no sistema Jabot, uma significativa quantidade desses dados não possui valores de coordenadas geográficas. Podemos melhor entender esse número a partir de uma visão histórica, pois o Sistema de Posicionamento Global (GPS) foi considerado completo apenas em 1995 e, 376.000 espécimes foram coletados anteriormente ao referido ano. Em termos percentuais, aproximadamente $80 \%$ das amostras dos acervos botânicos do JBRJ não possuem coordenadas. Essa lacuna limita diversos estudos como, por exemplo, a modelagem de distribuição de espécies e análises de conservação da vegetação (KAMINO et al. 20I2, MARTINELLI \& MORAES 20I3). Assim, acreditamos que a aplicação de uma metodologia para o georreferenciamento das coleções é necessária para recuperar ou validar a qualidade das coordenadas das amostras, mesmo que de forma aproximada, mas suficiente para viabilizar pesquisas e tomadas de decisão. 
O enriquecimento dos acervos, tanto preservados como vivos, só pode ser concretizado através de novas coletas. $O$ custo da realização de expedições de campo continua sendo um desafio para atingir todas as metas direta e indiretamente servidas pelas coleções e sistemas atualmente implantados no JBRJ. A integração dos profissionais responsáveis pelas coleções através de uma estratégia englobando todas as unidades é importante tanto para diminuir custos como para garantir melhor qualidade e intercâmbio de dados, economizando tempo e esforço dispendidos em digitalizar, limpar e organizar dados semelhantes para diferentes coleções.

Vale relembrar que, ao passo que o cumprimento das Metas I e 2 são uma responsabilidade repassada pelo Ministério do Meio Ambiente para esta instituição, as metas restantes não são de responsabilidade direta ou exclusiva do JBRJ, estando dispersas em diferentes projetos de outros institutos de pesquisa, jardins botânicos e universidades. Seria interessante contabilizar essas metas em termos nacionais para avaliar a situação do país no que diz respeito ao cumprimento das mesmas, e tomar medidas emergenciais que possibilitem seu incremento.

\section{Conclusões}

Acreditamos que, em função dos fatos expostos acima, temos grande possibilidade de chegar ao ano de 2020 com as Metas I e 2 cumpridas, mas para isso necessitamos que a infraestrutura desenvolvida para atender as demandas governamentais receba o apoio permanente de recursos, possibilitando assim a continuidade dos programas criados em resposta a esses objetivos. Outrossim, é necessário ampliar significativamente as coletas botânicas na Amazônia e em outros estados com lacunas de conhecimento através de grandes projetos de coleta que subsidiem com informações recentes o grande número de dúvidas a respeito de identidade e circunscrição de espécies. Essas coletas são tanto fundamentais como urgentes num país que, apesar de ser detentor da maior diversidade de plantas do planeta (FORZZA et al.20I2), destrói seus ambientes de maneira acelerada. Precisamos também desenvolver uma estratégia institucional de atividades que focalizem e incrementem a contribuição direta do JBRJ para as Metas 8, 9 e 13, além de esclarecer e incrementar a participação indireta da instituição no contexto das metas restantes.

\section{Agradecimentos}

Aos tecnologistas, técnicos e herborizadores das coleções botânicas do JBRJ por todo auxilio na preservação e ampliação dos acervos; ao programador Rafael Lima por todo seu empenho em construir e aprimorar um sistema que atendesse as necessidades das diferentes curadorias; a equipe de TI do JBRJ pelo dedicado trabalho para publicar e manter dados e imagens online. Ao CNPq, Faperj, Petrobras, SiBBr, Mellon Foundation, Natura, MCTI, MMA e pelo aporte financeiro. Rafaela C. Forzza é bolsista de produtividade do CNPq.

\section{Bibliografia}

Andrade, A.C.S. 2007. Identificação do comportamento de armazenamento no banco de sementes do Jardim Botânico do Rio de Janeiro: uma ferramenta estratégica para conservação vegetal. In:. Pereira, T.S ; Costa, M.L.M.N. \& Jackson, P.W. (Orgs.), Recuperando o verde para as cidades - a experiência dos jardins bo- 
tânicos brasileiros. Rio de Janeiro: Rede Brasileira de Jardins Botânicos; Jardim Botânico do Rio de Janeiro; BGCl. 208p.

Barros, C.F. \& Coradin, V.T.R. 20I5. Xilotecas brasileiras: panorama atual e perspectivas futuras. UNISANTA Bioscience 4(7): 29-40.

Barros, C.F.; Marquete, O. \& Callado C.H. 200I. A xiloteca: uma valiosa coleção de amostras de madeira. In: Marquete, N.F.S.; Carvalho, L.F.; Baumgratz, J.F. O herbário do Jardim Botânico do Rio de Janeiro: um expoente na história da flora brasileira. Jardim Botânico do Rio de Janeiro. Rio de Janeiro. Pp. 78-79.

Bediaga, B.; Lima, H.C.; Morim, M.P. \& Barros, C.F. 2008. Da aclimatação à conservação: as atividades científicas durante dois séculos. 200 anos do Jardim Botânico do Rio de Janeiro. Rio de Janeiro. Jardim Botânico do Rio de Janeiro. Rio de Janeiro. Pp. 33-42.

Brasil. 200I. Medida Provisória 2186-16, de 23 de agosto de 200I. Regulamenta o inciso II do $\S 1^{\circ}$ e o $\S 4^{\circ}$ do art. 225 da Constituição, os arts. $1^{\circ}, 8^{\circ}$, alínea "j", 10, alínea "c", I5 e 16, itens 3 e 4 da Convenção sobre Diversidade Biológica, dispõem sobre 0 acesso ao patrimônio genético, a proteção e o acesso ao conhecimento tradicional associado, a repartição de benefícios e o acesso à tecnologia e transferência de tecnologia para sua conservação e utilização, e dá outras providências. Brasília. DOU de 24/08/200I.

BFG. The Brazilian Flora Group 2015. Growing knowledge: an overview of seed plant diversity in Brazil. Rodriguésia 66(4): I085- I I I3.

Coelho, M.A.N. 2008. O inventário da coleção. In: Ormindo, P. (organizador). Guia de Árvores Notáveis - 200 anos do Jardim Botânico do Rio de Janeiro. Rio de Janeiro. Pp. 24-3I.

CDB 2002. Ministério do Meio Ambiente. www.cbd.int/doc/meetings/nbsap/ nbsapcbw-sam-0l/other/nbsapcbw-sam-0I-brasil-metas-indicadores.pdf

CDB 1992. Ministério do Meio Ambiente.www.mma.gov.br/estruturas/sbf_ chm_rbbio/_arquivos/cdbport_72.pdf

CDB 2012. Global Strategy for Plant Conservation: 201 I-2020. Botanic Gardens Conservation International, Richmond, UK. http://www.plants2020.net/ files/Plants2020/popular_guide/englishguide.pdf

Coradin, L. 20I I. A iniciativa plantas para o futuro. In: Coradin, L.; Siminski, A.; Reis, A. Espécies da flora nativa de valor econômico atual ou potencial. Série Biodiversidade 40: 25-64.

Costa, M.L.M.N. 2014. Conservação de espécies ameaçadas de extinção nos jardins botânicos brasileiros. Tese de Doutorado. Jardim Botânico do Rio de Janeiro. 126p.

Costa, D.P. \& Peralta, D. 2015. Bryophytes diversity in Brazil. Rodriguésia 66(4): |063-I07|.

Engels, J.M.M., Maggioni, L., Maxted, N. and Dulloo, M.E. 2008. Complementing in situ conservation with ex situ measures. In J. Iriondo, N. Maxted and M.E. Dulloo (eds). Conserving Plant Genetic Diversity in Protected Areas. Pp 169-I8I. CAB International, Wallingford, UK

FAO, 20I4. Plan de acción mundial para la conservación, la utilización sostenible y el desarrollo de los recursos genéticos forestales. http://www.fao.org/3/ai3849S.pdf 
Rafaela Campostrini Forzza, Anibal Carvalho Jr., Antônio Carlos S.Andrade, Luciana Franco, Luís Alexandre Estevão, Viviane S. Fonseca-Kruel, Marcus A. Nadruz Coelho, Neusa Tamaio, Daniela Zappi

FAO, 20I5. Lessons learned about ways and means to conserve and use genetic diversity to build resilience to climate change in food and agriculture systems - survey report (solo en inglés) CGRFAI5/I5/Inf.I6. http://www.fao.org/3/amm50le.pdf

Forzza, R.C., Baumgratz, J.F.A., Bicudo, C.E.M., Canhos, D.A.L., Carvalho Jr., A.A., Coelho, M.A.N., Costa, A.F., Costa, D.P., Hopkins, M.G., Leitman, P.M., Lohmann, L.G., Lughadha, E.N., Maia, L.C., Martinelli, G., Menezes, M., Morim, M.P., Peixoto, A.L., Pirani, J.R., Prado, J., Queiroz, L.P., Souza, S., Souza, V.C., Stehmann, J.R., Sylvestre, L.S., Walter, B.M.T. \& Zappi, D.C. 2012. New Brazilian floristic list highlights conservation challenges. BioScience 62(I): 39-45.

Forzza, R.C.; Baumgratz, J.F.A.; Bicudo, C.E.M.; Carvalho Jr.A.A.; Costa,A.; Costa, D.P.; Hopkins, M.; Leitman, P.M.; Lohmann, L.G.; Maia, L.C.; Martinelli, G.; Menezes, M.; Morim, M.P.; Coelho, M.A.N.; Peixoto, A.L.; Pirani, J.R.; Prado, J.; Queiroz, L.P.; Souza,V.C.; Stehmann, J.R.; Sylvestre, L.S.;Walter, B.M.T. \& Zappi, D. (Eds.). 2010. Catálogo de plantas e fungos do Brasil, v. I - II. Jardim Botânico do Rio de Janeiro. Rio de Janeiro.

Forzza, R.C.; Mynssen, C.M.; Tamaio, N.; Barros, C.; Franco, L.; Pereira, M.C.A. 2008. As coleções do herbário. 200 anos do Jardim Botânico do Rio de Janeiro. Rio de Janeiro. Jardim Botânico do Rio de Janeiro. Rio de Janeiro. Pp. 45-55.

Forzza, R.C.; Carvalho Jr.,A.;Andrade,A.C.S.; Franco, L.; Nadruz, M.;Tamaio, N. \& Fonseca-Kruel,V.S. 20I5a. Herbário do Jardim Botânico do Rio de Janeiro (RB). UNISANTA Bioscience 4(6): 393-398.

Forzza, R.C.; Filardi, F.L.R; Condack, J.P.S;Accardo Filho, M.A.P.; Leitman, P.; Monteiro, S.H.N. \& Monteiro, V.F. 20 I 5b. Herbário Virtual Reflora. UNISANTA Bioscience 4(7): 88-94.

Gonzalez, M. 2009. Quantificação de custo e tempo no processo de informatização das coleções biológicas brasileiras: a experiência do herbário do Instituto de Pesquisas Jardim Botânico do Rio de Janeiro. Rodriguésia 60(3): 7I I-72I.

Gross T.; Johnston S.; Barber C.V. 2005. A Convenção sobre Diversidade Biológica: entendendo e influenciando o processo. Brasília, Instituto de Estudos Avançados das Nações Unidas.

Havens, K.;Vitt, P.; Maunder, M.; Guerrant Jr., E.O. \& Dixon, K. 2006. Ex Situ Plant Conservation and Beyond. BioScience 56 (6): 525-53I.

Hopkins, M.J. 2007. Modeling the known and unknown plant biodiversity of the Amazon Basin. Journal of Biogeography 34: I400-I4II.

International Society of Ethnobiology. 2006. International Society of Ethnobiology Code of Ethics (with 2008 additions). http://ethnobiology.net/code-of-ethics/

IIED. 20I5. Biocultural Heritage: Promoting resilient farming systems and local economies. http:// http://biocultural.iied.org/

IUCN (International Union for Conservation of Nature and Natural Resources). 200I. IUCN Red List Categories and Criteria, Version 3.I. IUCN Species Survival Commission, Gland (Switzerland) and Cambridge (UK). 30p.

JBRJ. 2016. Instituto de Pesquisas Jardim Botânico do Rio de Janeiro. Jabot - Banco de Dados da Flora Brasileira. Disponível em: [http://www.jbrj.gov.br/jabot]. Acesso em 15 de fevereiro de 2016. 
Kamino, L.H.Y.; Stehmann, J.R.; Amaral, S.; De Marco, P.; Rangel, F.; Siqueira, M.F; De Giovanni, R. \& Hortal, J. 20I2. Challenges and perspectives for species distribution modelling in the neotropics. Biology Letters 8(3): 324-326.

Kury,A.B. et al. 2006. Diretrizes e estratégias para a modernização de coleções biológicas e a consolidação de sistemas integrados de informação sobre biodiversidade. Brasília: Centro de Gestão e Estudos Estratégicos: Ministério da Ciência e Tecnologia. 324 pp.

Maia, L.C.; Carvalho Júnior,A; Cavalcanti, L.H.; Gugliotta,A.M.; Drechsler-Santos, E.R.; Santiago, A.L.M.A.; Ca冈ceres, M.E.S.; Gibertoni, T.B.; Aptroot, A.; Giachini, A.J.; Soares,A.M.S.; Silva, A.C.G.; Magnago,A.C.; Goto, B.T.; Lira, C.R.S.; Montoya, C.A.S.; Pires-Zottarelli, C.L.A.; Silva, D.K.A.; Soares, D.J.; Rezende, D.H.C.; Luz, E.D.M.N.; Gumboski, E.L.; Wartchow, F.; Karstedt, F.; Freire, F.M.; Coutinho, F.P.; Melo, G.S.N.; Sota囚o, H.M.P.; Baseia, I.G.; Pereira, J.; Oliveira, J.J.S.; Souza, J.F.; Bezerra, J.L.;Araujo Neta, L.S.; Pfenning, L.H.; Gusma囚o, L.F.P.; Neves, M.A.; Capelari, M.; Jaeger, M.C.W.; Pulgari冈n, M.P.; Menolli Junior, N.; Medeiros, P.S.; Friedrich, R.C.S.; Chikowski, R.S.; Pires, R.M.; Melo, R.F.; Silveira, R.M.B.; Urrea-Valencia, S.; Cortez, V.G. \& Silva, V.F. 20I5. Diversity of Brazilian Fungi. Rodrigue冈sia 66(4): 1033-1045.

\section{MMA 20I4. PORTARIA No 443, DE I7 DE DEZEMBRO DE 2014.}

Martinelli, G. \& Moraes, M. 20I3. Livro vermelho da flora do Brasil. Rio de Janeiro. Andrea Jakobsson. Instituto de Pesquisas Jardim Botânico do Rio de Janeiro. I I00p.

Martinelli, G., Messina, T. \& Santos Filho, L. 20I4. Livro Vermelho da Flora do Brasil: Plantas Raras do Cerrado. Andrea Jakobsson: Instituto de Pesquisas Jardim Botânico do Rio de Janeiro: CNCFlora. 320p.

Menezes, M.; Bicudo, C.E.M.; Moura, C.W.N.; Alves, A.M.; Santos, A.A.; Pedrini, A.G.;Arau囚jo,A.;Tucci,A.; Fajar,A.; Malone, C.; Kano, C.H.; Sant'Anna, C.L.; Branco, C.Z.; Odebrecht, C.; Peres, C.K.; Neuhaus, E.B.; Eskinazi-Leca, E.; Aquino, E.; Nauer, F.; Santos, G.N.;Amado Filho, G.M.; Lyra, G.M.; Borges, G.C.P.; Costa, I.O.; Nogueira, I.S.; Oliveira, I.B.; Paula, J.C.; Nunes, J.M.C.; Lima, J.C.; Santos, K.R.S.; Ferreira, L.C.; Gestinari, L.M.S.; Cardoso, L.S.; Figueiredo, M.A.O; Silva, M.H.; Barreto, M.B.B.B.; Henriques, M.C.O; Cunha, M.G.G.S.; Bandeira-Pedrosa, M.E.; Oliveira-Carvalho, M.F.; Sze冈chy, M.T.M.; Azevedo, M.T.P.; Oliveira, M.C.; Cabezudo, M.M.; Santiago, M.F.; Bergesh, M.; Fujii, M.T.; Bueno, N.C.; Necchi Jr., O.; Jesus, P.B.; Bahia, R.G.; Khader, S.; Alves-da-Silva, S.M.; Guimara冈es, S.M.P.B.; Pereira, S.M.B.; Caires, T.A.; Meurer, T.; Cassano,V.;Werner,V.R.; Gama Jr.,W.A. \& Silva,W.J. 2015. Update of the Brazilian floristic list of Algae and Cyanobacteria. Rodrigue区sia 66(4): 1047-1062.

Nesbitt, M. 2014. Use of herbarium specimens in ethnobotany. In: Curating biocultural collections: a handbook. Edited by J. Salick, K. Konchar, and M. Nesbitt. Kew: Royal Botanic Gardens, Kew. pp. 313-328.

Pereira, T.S. \& Costa, M.L.N. 2010. Os Jardins Botânicos brasileiros: desafios e potencialidades. CiênciaCultura 62 (I): 23-25. http://cienciaecultura.bvs.br

Pimm, S.L.; Russell, G.J.; Gittleman, J.L. \& Brooks, T.M. 1995:The future of biodiversity. Science 269, 347-50.

Prado, J.; Sylvestre, L.S.; Labiak, P.H.;Windisch, P.G.; Salino, A.; Barros, I.C.L.; Hirai, R.Y.; Almeida, T.E.; Santiago, A.C.P.; Kieling-Rubio, M.A.; Pereira, A.F.N.; Øllgaard, B.; Ramos, C.G.V.; Mickel, J.T.; Dittrich,V.A.O.; Mynssen, C.M.; Schwartsburd, P.B.; 
Rafaela Campostrini Forzza, Anibal Carvalho Jr., Antônio Carlos S.Andrade, Luciana Franco, Luís Alexandre Estevão,Viviane S. Fonseca-Kruel, Marcus A. Nadruz Coelho, Neusa Tamaio, Daniela Zappi

Condack, J.P.S.; Pereira,J.B.S \& Matos, F.B. 20I5. Diversity of ferns and lycophytes in Brazil. Rodriguésia 66(4): 1073-1083.

Shepherd, G.J. 2005. Plantas Terrestres. In: Lewinsohn, T.M. (org.). Avaliação do estado do conhecimento da biodiversidade brasileira. Série Biodiversidade I5(2): 145-192.

Sobral,M.\& Stehmann,J.R.2009.An analysis of newAngiosperm species siscoveries in Brazil (1990-2006). Taxon 58(I): 227-232.

Systematics Agenda 2000. 1994. Charting the Biosphere (Technical Report), pp. I-33.

The Declatation of Belém, 2004. In: PLENDERLEITH, K. (Ed.). Indigenous knowledge and ethics: a Darrell Posey reader. New York: Routledge, pp. 208-209.

Valente, M.C.; Baumgratz, J.F.; Marquete, N.F.S. \& Carvalho, L.F. 200I.A história do herbário e seu acervo. In: Marquete, N.F.S.; Carvalho, L.F.; Baumgratz, J.F. O herbário do Jardim Botânico do Rio de Janeiro: um expoente na história da flora brasileira. Jardim Botânico do Rio de Janeiro. Rio de Janeiro. Pp. I5-23.

Walters, C. \& Engels, J. 1998. The effects of storing seeds under extremely dry conditions. Seed Science Research 8 (supplement I): 3-8.

World Resouces Institute;The World Conservation Union; United Nations Enviroment Programme 1992. A Estratégia Global da Biodiversidade. 1992. Paraná: Fundação O Boticário de Proteção à Natureza (tradução). 232p.

Wolfe, J. Bryant, G. 200I. Cellular cryobiology: thermodynamic and mechanical effectes. Internacional Journal of Refrigeration, Surrey 24: 438-450.

Artigo recebido em janeiro de 2016. Aprovado em abril de 2016 
Coleções Biológicas do Jardim Botânico do Rio de Janeiro À Luz das Metas da GSPC/CDB:

Onde Estaremos em 2020?

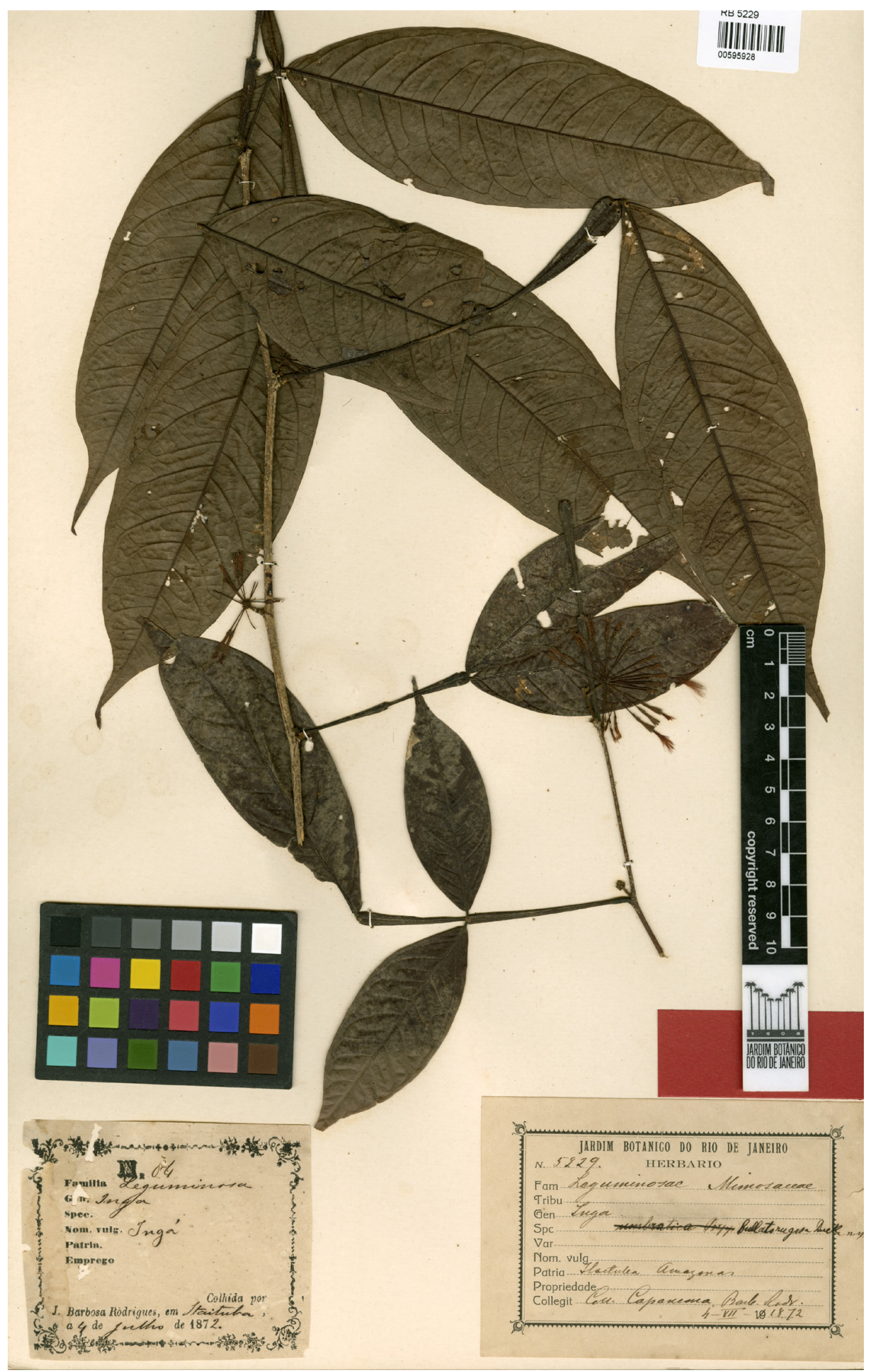

Figura I: Uma das exsicatas coletadas por João Barbosa Rodrigues, fundador do herbário RB. 
Rafaela Campostrini Forzza, Anibal Carvalho Jr., Antônio Carlos S.Andrade, Luciana Franco, Luís Alexandre Estevão,Viviane S. Fonseca-Kruel, Marcus A. Nadruz Coelho, Neusa Tamaio, Daniela Zappi
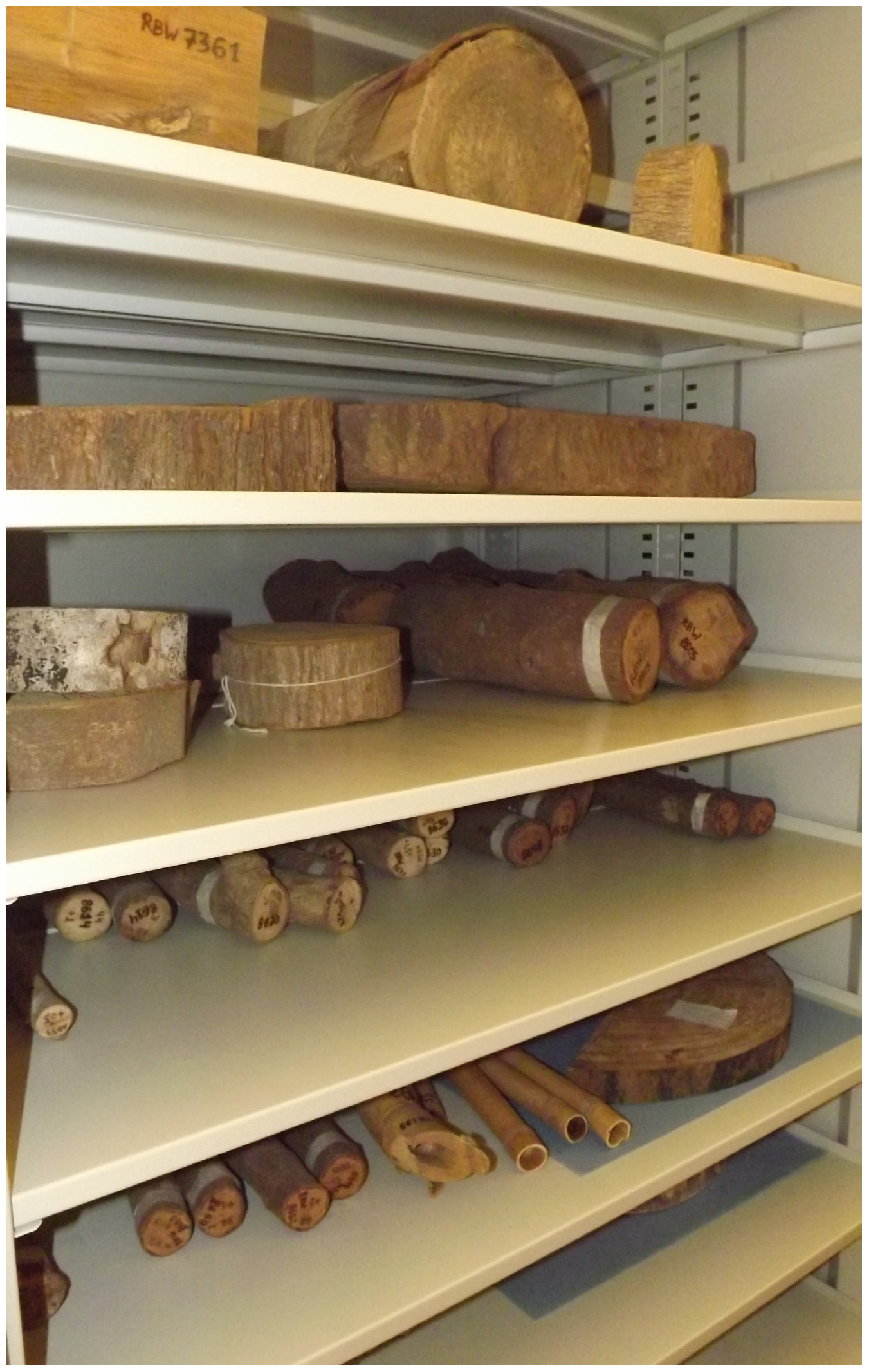

Figura 2:Amostras da coleção de madeiras (xiloteca). 
Coleções Biológicas do Jardim Botânico do Rio de Janeiro À Luz das Metas da GSPC/CDB:

Onde Estaremos em 2020?

154

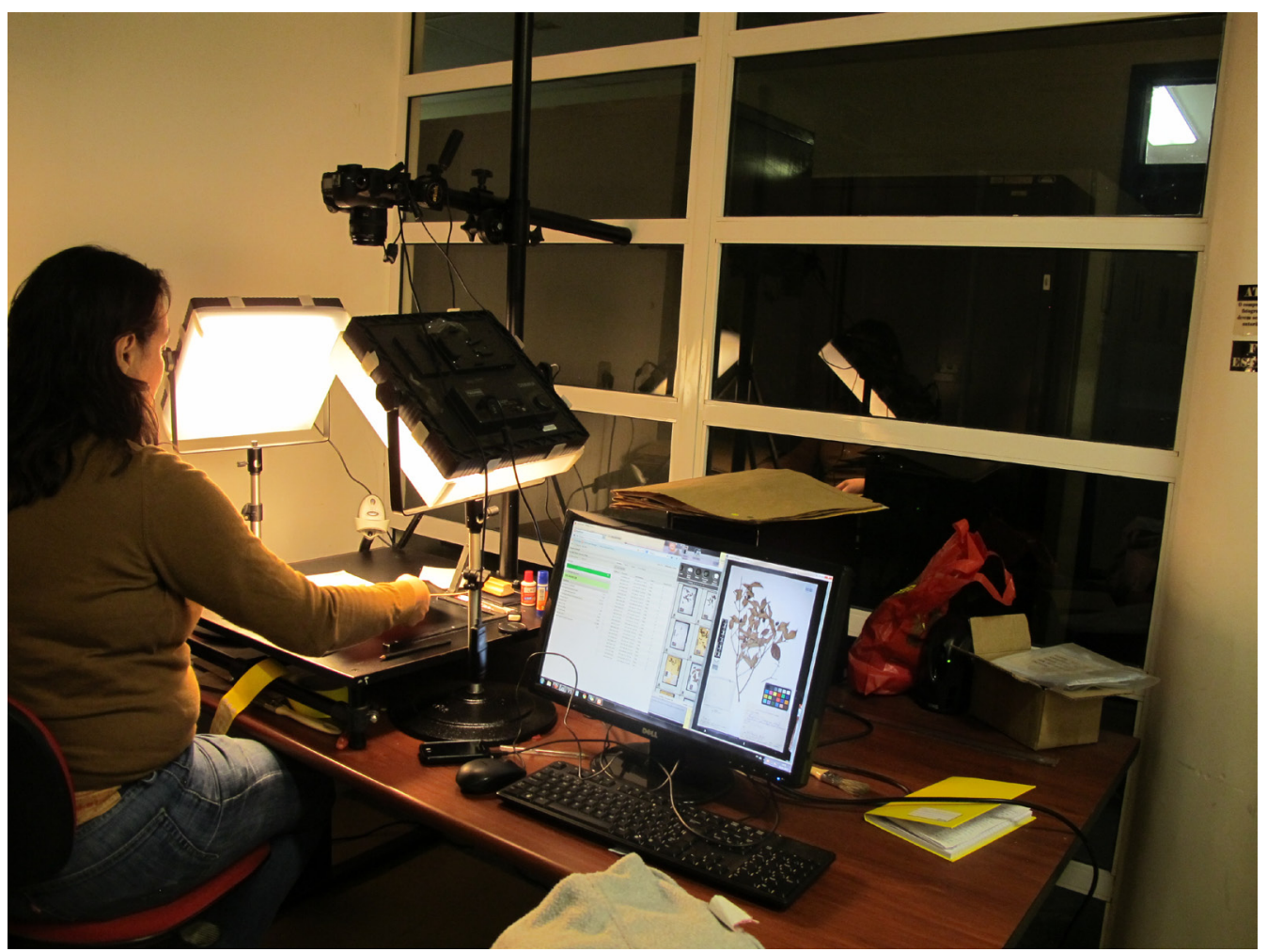

Figura 3: Processo de digitalização dos espécimes.
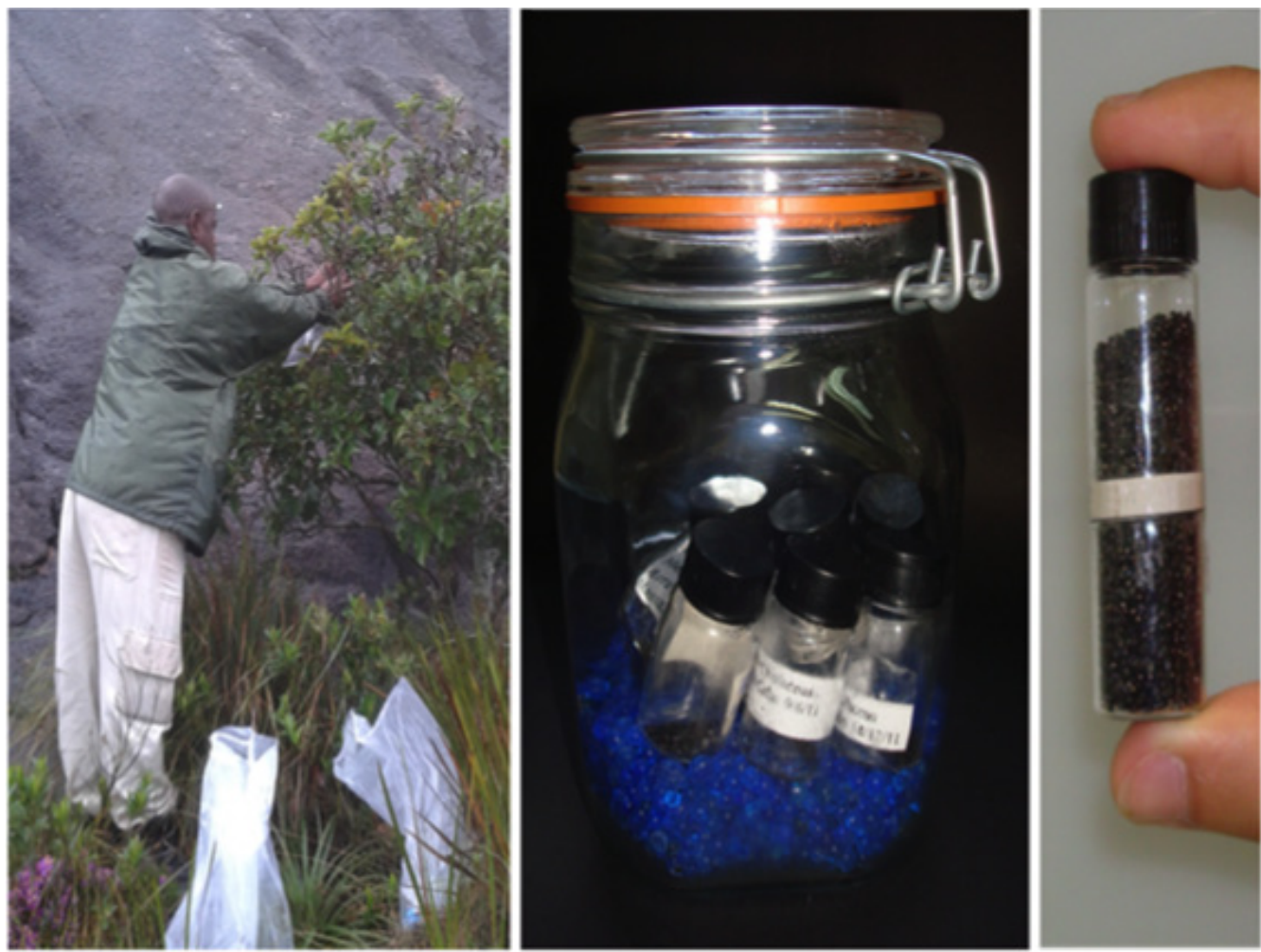

Figura 4: Coleta, embalagem e conservação de sementes de espécies ameaçadas de extinção. 


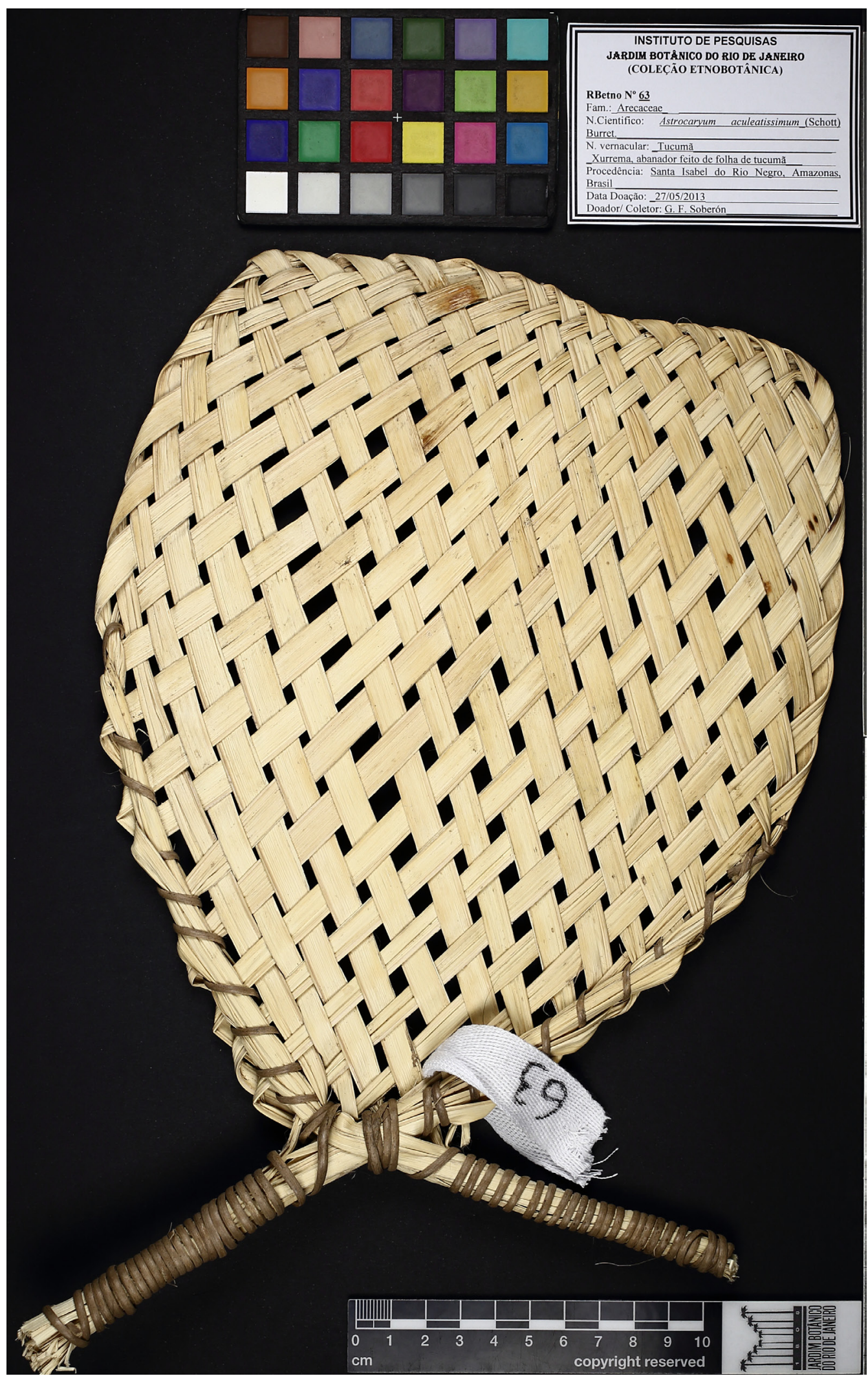

Figura 5: Uma das amostras depositada no banco de DNA. 
Coleções Biológicas do Jardim Botânico do Rio de Janeiro À Luz das Metas da GSPC/CDB:

Onde Estaremos em 2020?

156

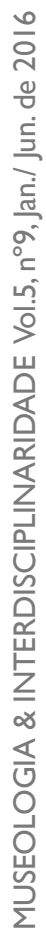

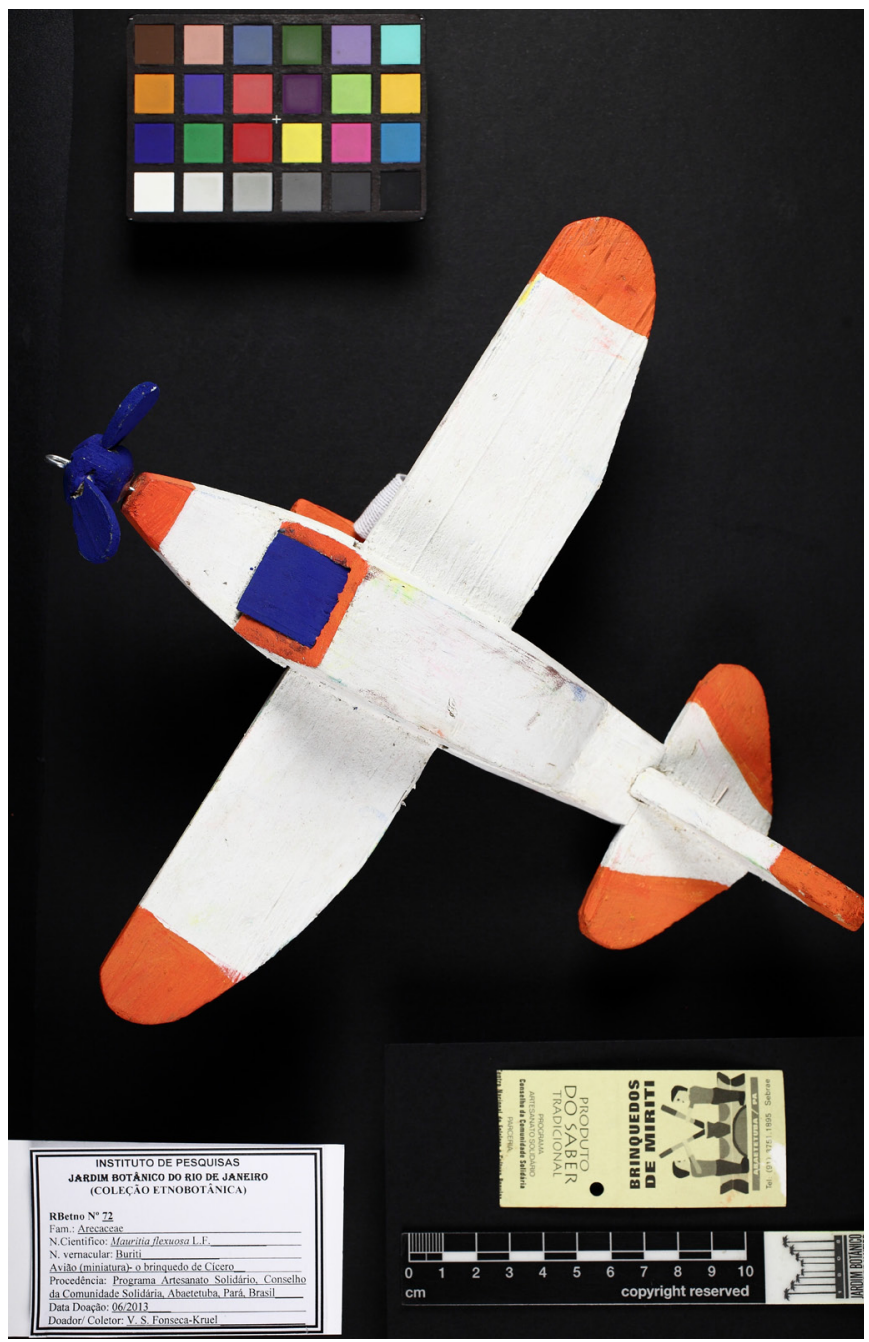

Figuras 6 e 7: Espécimes do acervo etnobotânico.

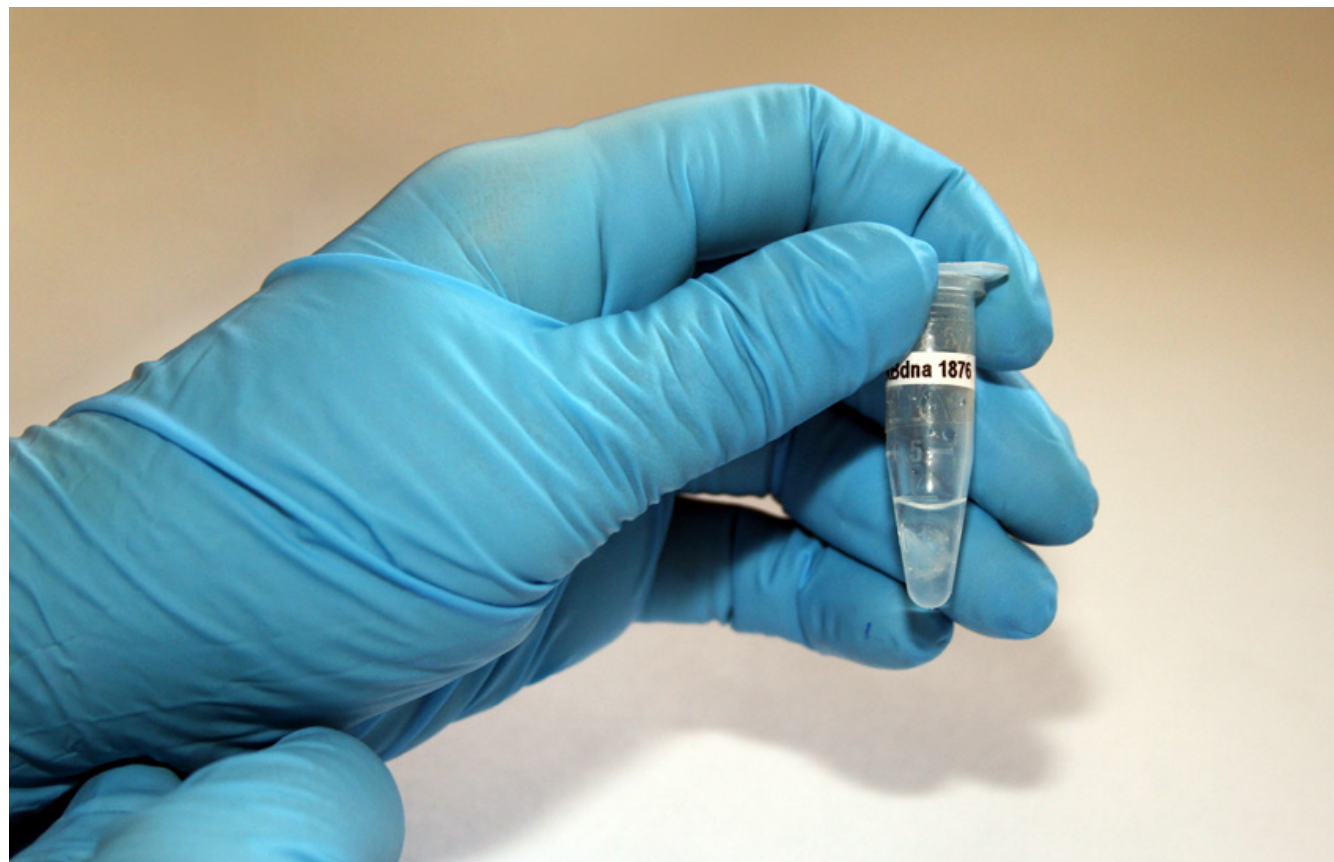


Rafaela Campostrini Forzza, Anibal Carvalho Jr., Antônio Carlos S.Andrade, Luciana Franco, Luís Alexandre Estevão, Viviane S. Fonseca-Kruel, Marcus A. Nadruz Coelho, Neusa Tamaio, Daniela Zappi

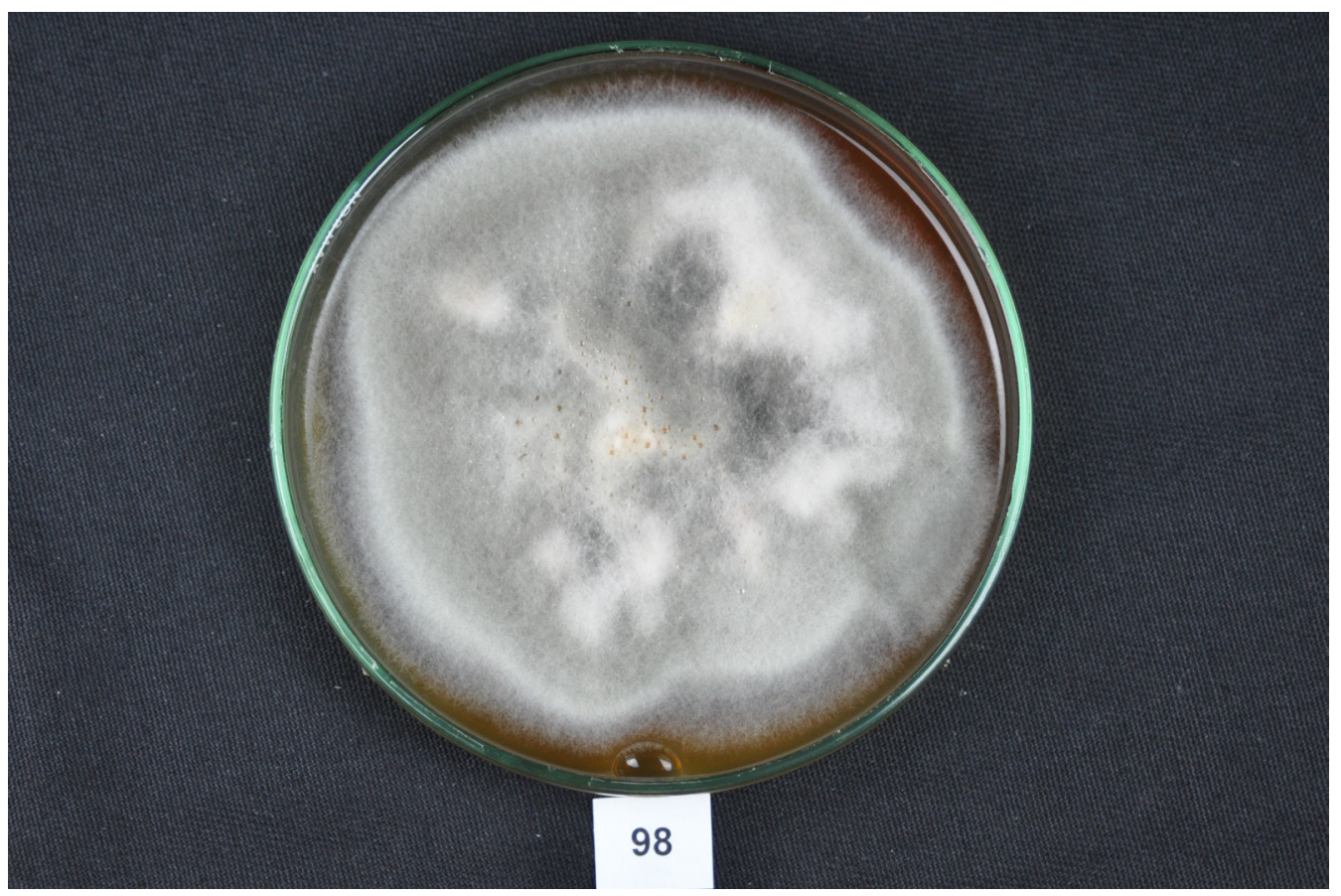

Figura 8: Espécime da coleção de fungos. Isolamento em meio de Agar Batata (BDA) de Alternaria tomatophila E.G. Simmons a partir de sintomas de Solanum lycopersicum L.

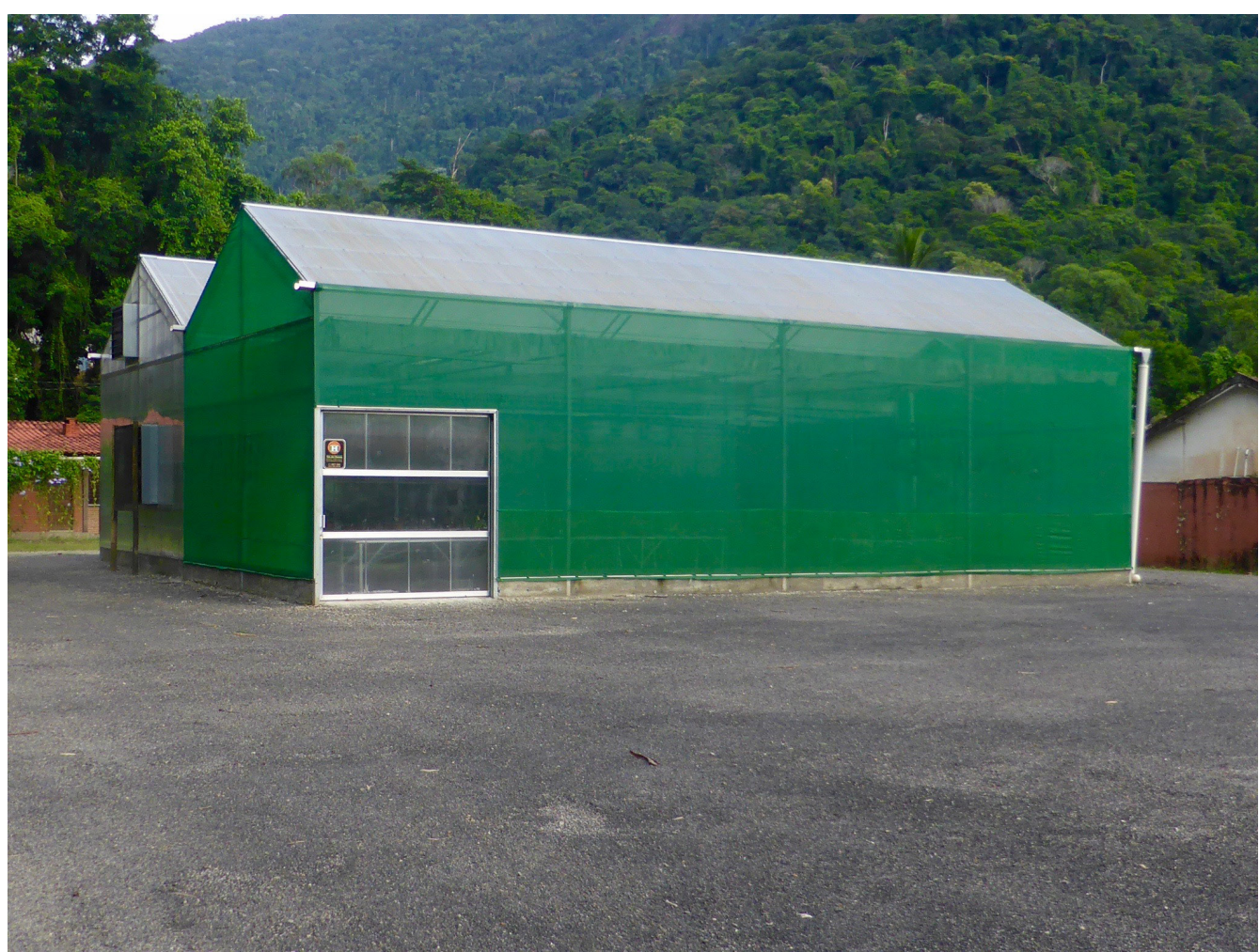

Figura 9: Nova estufa construída na área ampliada do JBRJ para abrigar a coleção de orquídeas. Foto: M. Nadruz. 


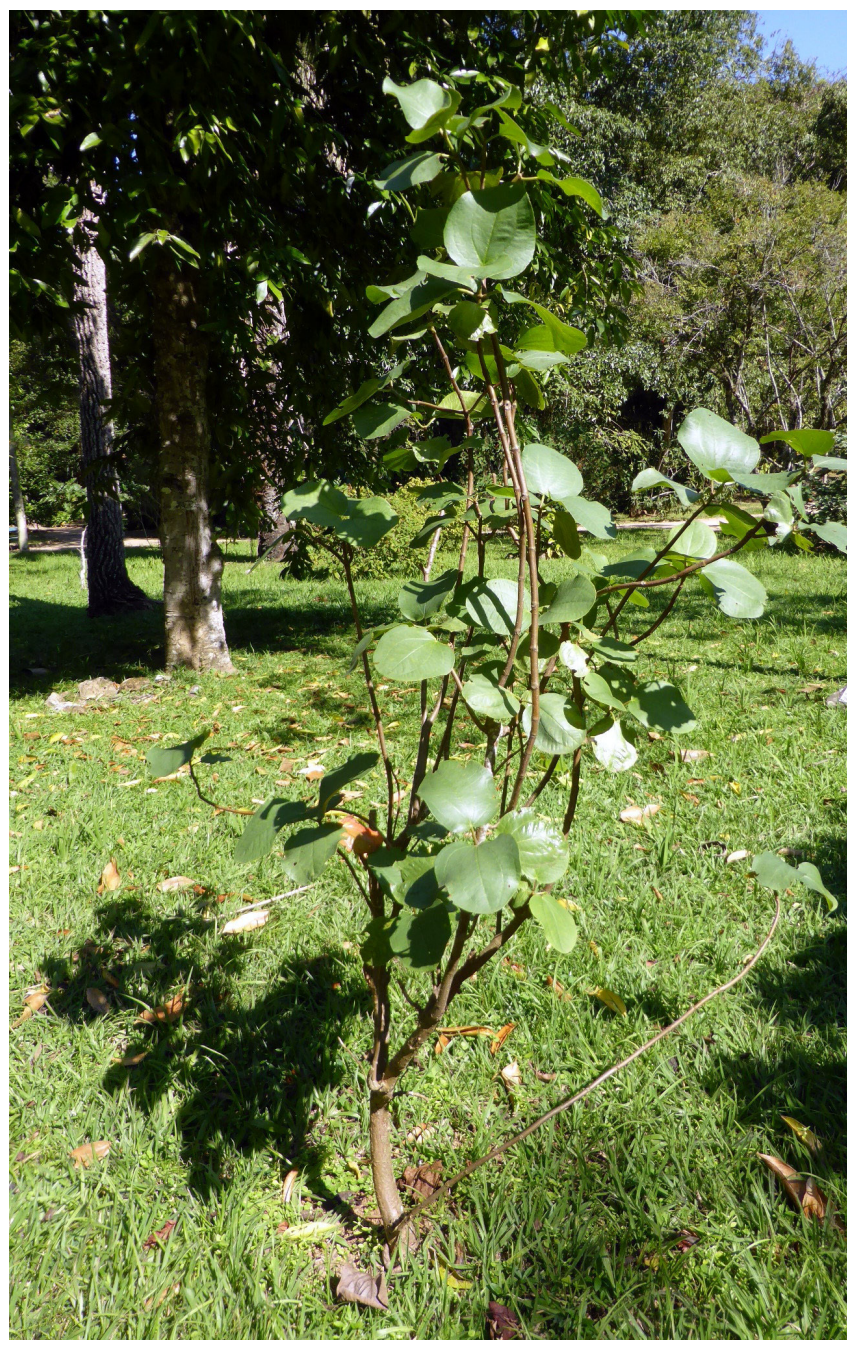

Figuras 10 e II: Merianthera pulchra Kuhlm. (Melastomataceae), uma das espécies brasileiras ameaçadas de extinção cultivada no JBRJ. Foto 9: M. Nadruz; I0 C.N. Fraga.

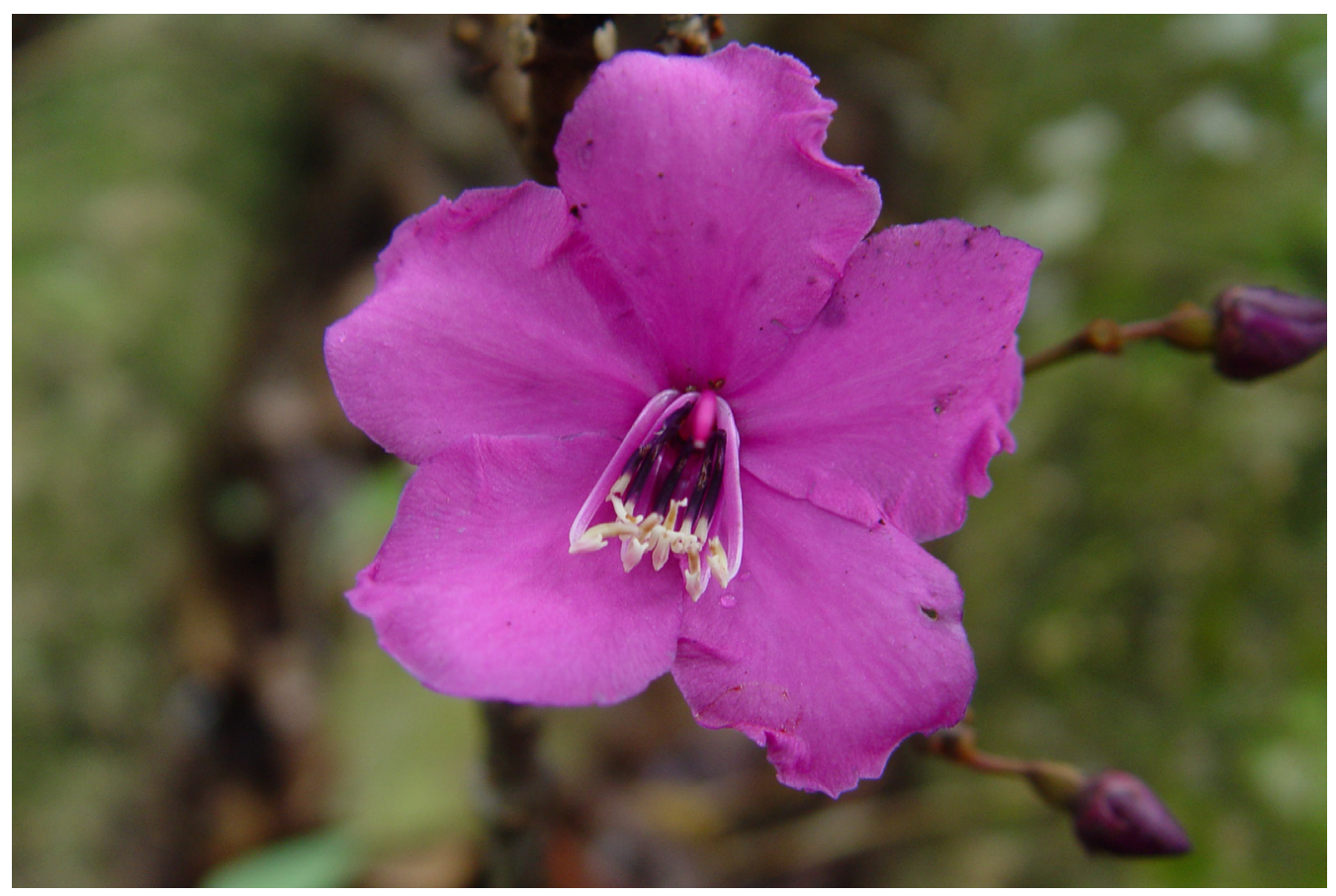


Rafaela Campostrini Forzza, Anibal Carvalho Jr., Antônio Carlos S.Andrade, Luciana Franco, Luís Alexandre Estevão,Viviane S. Fonseca-Kruel, Marcus A. Nadruz Coelho, Neusa Tamaio, Daniela Zappi

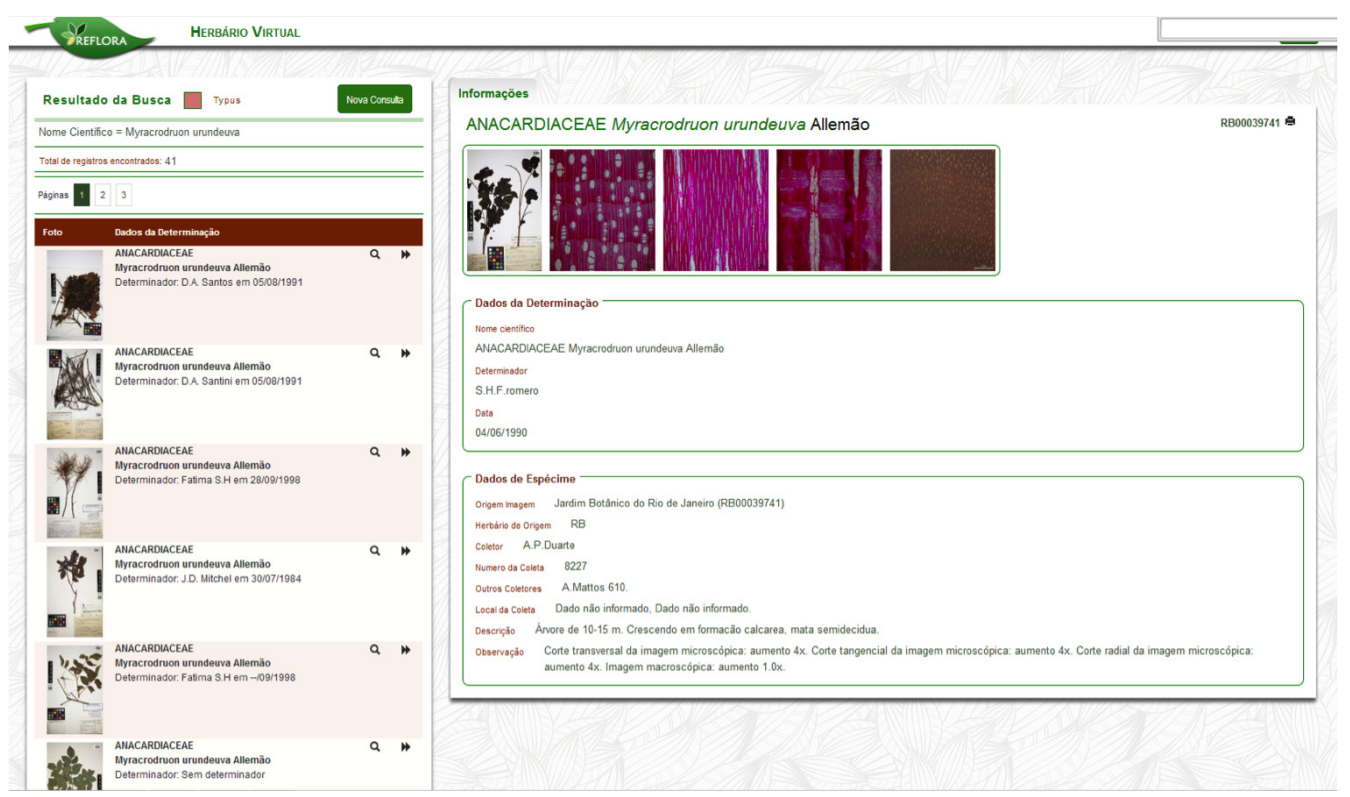

Figura 12: Imagem de exsicatas do RB e da xiloteca (RBw) publicadas no Herbário Virtual Reflora. 